\title{
Correlation between Rheological Fatigue Tests on Bitumen and Various Cracking Tests on Asphalt Mixtures
}

\author{
Muhammad Aakif Ishaq and Filippo Giustozzi *(D) \\ Civil and Infrastructure Engineering, School of Engineering, RMIT University, Melbourne, VIC 3001, Australia; \\ s3647650@student.rmit.edu.au \\ * Correspondence: filippo.giustozzi@rmit.edu.au; Tel.: +61-3-99252035
}

Citation: Ishaq, M.A.; Giustozzi, F. Correlation between Rheological Fatigue Tests on Bitumen and Various Cracking Tests on Asphalt Mixtures. Materials 2021, 14, 7839. https:// doi.org/10.3390/ma14247839

Academic Editor: Giovanni Polacco

Received: 28 October 2021

Accepted: 10 December 2021

Published: 17 December 2021

Publisher's Note: MDPI stays neutral with regard to jurisdictional claims in published maps and institutional affiliations.

Copyright: (c) 2021 by the authors. Licensee MDPI, Basel, Switzerland. This article is an open access article distributed under the terms and conditions of the Creative Commons Attribution (CC BY) license (https:/ / creativecommons.org/licenses/by/ $4.0 /)$.

\begin{abstract}
Accurate characterisation and appropriate binder selection are essential to increase the load-induced cracking resistance of asphalt mixtures at an intermediate temperature. Hence, the primary goal of this study was to correlate the cracking resistance exerted by the binder with the cracking performance of asphalt mixtures. The laboratory-based experimental plan covered various types of laboratory tests specified by various agencies and road authorities to study the correlation of a neat bitumen and five polymer-modified binders with their corresponding asphalt mixtures. The fatigue life of the binders was assessed through a Linear Amplitude Sweep (LAS) test and statistically correlated with various load-induced cracking parameters from the indirect tensile test, semi-circular bending (SCB) test, and four points bending beam test (FPBB) of asphalt mixtures at $25^{\circ} \mathrm{C}$. Binders and mixes were further grouped depending on their polymeric family (i.e., modified with a particular type of polymer) to validate their statistical correlation. The indicator that mostly correlated the binder properties with the asphalt mixture properties is the secant modulus from the SCB test. Fatigue parameters obtained through LAS better explain the asphalt fatigue performance obtained through FPBB; specifically, asphalt tests at high strain levels (e.g., 400 micro strain) better correlate to the LAS fatigue parameter (Nf).
\end{abstract}

Keywords: fatigue; cracking; bitumen; asphalt; tensile strength; fracture energy; dissipated energy

\section{Introduction}

Asphalt pavements are affected by three major deterioration mechanisms: moisture damage, cracking, and permanent deformation [1-4]. Traffic-induced cracking of flexible pavements manifests as alligator cracking on the pavement's surface due to recurrent stresses and strains produced by cyclic loading at an intermediate temperature [5-7]. Cracking on pavements depends on the road pavement structure (i.e., layer thickness, stiffness modulus, and rheological properties of bitumen), traffic, environmental conditions, and the time-dependent variation (aging) of bitumen [8]. In addition to the deterioration of the pavement's structural integrity, cracking also reduces the road functionality, including safety, comfort, and operating expenses for the user [9].

Although many variables influence the cracking behaviour of asphalt mixes (i.e., ambient conditions, mixture properties, traffic loading, binder, and aggregate properties), the binder is said to perform the most critical function $[6,10,11]$. The vulnerability to cracking increases when the bitumen stiffens due to environmental aging, increasing its capacity to form cracks from repeated traffic stresses [12]. The durability of asphalt pavements can be enhanced by appropriate binder selection and precise characterisation of the asphalt binders $[13,14]$.

Bitumen modification, an effective tool for making asphalt roads more durable and less susceptible to rutting, has advanced in recent decades $[15,16]$. However, finding a binder that can endure cracking remains a problem due to a lack of research investigating how polymer-modified binders resist long-term fatigue cracking when incorporated into 
asphalt mixes in the field under actual traffic loading. One explanation for this may be associated to a deficiency in testing methods that allows for assessing binder's cracking characteristics. Most of the past advancements in rheological testing are limited to the domain of linear viscoelastic behaviour with relatively small deformations [17].

Moreover, several agencies worldwide continue to use empirical tests to characterise binder performance at intermediate temperatures. This situation has been exacerbated further by the recent invention of several new asphalt binders, including hybrid (i.e., combining more than one polymer) binders, binders that are specifically modified using waste materials (crumb rubber, plastic, etc.), and high-performance binders for specialised applications (for example, airport pavements) [18-22]. Conventional and commonly used binder tests that may be generally associated with cracking resistance comprise of (i) traditional empirical tests, such as direct tensile test, ductility, and penetration; (ii) time sweep tests; (iii) linear viscoelastic rheology using a dynamic shear rheometer (DSR) and more advanced rheological tests, such as a LAS test [23,24].

In the Superpave study, the $G^{*} \sin \delta$ parameter (phase angle $\delta$ and complex shear modulus $\left.\left|G^{*}\right|\right)$ is used to quantify the fatigue resistance of the asphalt binder [25]. For strain-controlled testing, Strategic Highway Research Program (SHRP) researchers assumed that a lower dissipated energy of each loading cycle $\left[\mathrm{w}_{\mathrm{i}}=\pi \varepsilon \mathrm{G}^{*} \sin \delta\right]$ correlates to a lesser accumulation of distress, hence implying that asphalt with a lower $G^{*} \sin \delta$ value would be more resistant to fatigue cracking. The use of $\mathrm{G}^{*} \sin \delta$ to evaluate fatigue cracking performance of polymer-modified asphalts has been associated with some drawbacks by several studies [26-30]. The complex polymer structures are not activated when such material characteristics are measured predominantly in the small strains domain and inside the linear viscoelastic zone; therefore, the full advantages of polymer modification are not highlighted by this parameter [27]. However, in a limited number of investigations, the $G^{*}$ $\sin \delta$ parameter strongly correlated with the fatigue cracking of polymer-modified asphalt mixtures tested using various testing techniques $[15,25,31,32]$.

The linear amplitude sweep (LAS) is considered a more advanced test in the fatigue characterisation of bitumen. It was devised as an expedited fatigue test to substitute for the time-sweep test [33]. The strain amplitude is gradually increased in a systematically linear method to achieve faster damage of the sample. The LAS test analysis is based on the viscoelastic continuum damage (VECD) model, which has been widely used to characterise and predict the fatigue performance of asphalt mixes [34-37]. The subsequent damage characteristic relationship can be utilised in the strain-based fatigue simulation, which enables fatigue life to be predicted at any given stress amplitude, frequency, and temperature. The results of fatigue prediction were shown to have a reasonable correlation with field cracking measured in asphalt pavements [38]. Tables 1-5 summarise the critical literature on correlations between various binder properties and cracking of asphalt mixes.

Similar to binders, various tests are available to evaluate the cracking of asphalt mixes, which assist in predicting the performance of the pavement in the field. Cracking at intermediate temperatures can be evaluated using crack initiation (fatigue cracking) and the crack propagation concept (fracture resistance properties). The need to study these two mechanisms is because of the elastic recovery properties of binders imparted by their viscoelastic nature. Hence, a crack (fracture) produced by a single traffic-induced load does not lead to a significant cracking; instead, recurrent stresses and strains by traffic-induced loads result in significant cracking that manifests itself as alligator cracking (fatigue cracking). Therefore, knowing the potential of crack initiation and then crack propagation can help characterise the asphalt mixtures more comprehensively.

Many laboratory testing protocols have been developed to quantify cracking resistance of asphalt mixtures whether under dynamic or static loads, but no unique consensus has been achieved on which one should be universally adopted [39]. Among the many tests are the Fenix test [40], single-edge notched beam [41], semi-circular bending test [42-44], dog-bone direct tension [45], overlay test [46,47], indirect tension test [48-50], disc-shaped compact tension [49], and IDT asphalt cracking test [51]. For dynamic testing specifi- 
cally, a more detailed explanation around the benefits and drawbacks of fatigue testing methodologies can be found in $[39,52]$.

IDT and SCB are some of the candidate tests for studying the crack propagation phenomenon by characterising the fracture resistance properties of the asphalt mixtures [53-57]. The IDT and SCB test techniques are typically employed to determine an asphalt sample's maximum tensile strength, slope, and fracture energy at intermediate temperatures. SCB test method is based on the fracture mechanics concept with low variability in test results and has been used to determine the fracture resistance of the asphalt mixtures. The IDT test technique is utilised as a performance-based quality control tool during the design and manufacture of asphalt mixtures and for estimating the cracking potential [58,59]. Both IDT and SCB tests are elementary and can be carried out using standard laboratory equipment, frequently available in any asphalt plants' laboratory.

The most popular tests for investigating the fatigue cracking potential are categorised as (i) simple flexure tests (designed to create a direct connection between fatigue life and stress/strain by subjecting beams to pulsing or sinusoidal loads in either a third or centrepoint layout, rotating cantilever beams, and trapezoidal cantilever beams), such as rotating cantilever, two-point loading on trapezoidal specimens, three-point loading, and four point loading on prismatic specimens; (ii) direct axial loading tests (pulsing or sinusoidal loads applied uniaxially with or without stress reversal), such as push-pull or tensioncompression on cylindrical specimens; and (iii) diametral loading test (pulsing loads to diametral cylindrical specimens), namely, uniaxial repeated loading tests on cylindrical specimens. These tests use pulsing loads on cylindrical specimens in the diametral direction to build a direct link between fatigue life and stress/strain [17,60-64]. Generally, factors that differentiate among suitable fatigue cracking laboratory tests are convenience or userfriendliness, sample manufacturing time, test duration, cost efficiency, correlation with field performance, multi-data generation capabilities, and adaptability to well-established asphalt mix design and screening procedures.

The VECD approach is gaining popularity as a viable tool for determining the durability of asphalt mixtures against fatigue cracking during uniaxial tests (i.e. push-pull tests). The applicability of constitutive models, such as VECD, is favourable over the lengthier FPBB. In addition, uniaxial fatigue tests promote a constant stress state in the specimen section, hence better representing asphalt's fundamental properties. As a downside, uniaxial tests commonly require parallel surfaces of the samples to run, hence requiring cutting of the sample and consequent gluing to the testing jig. Seitllari and Kutay have recently devised a novel technique for determining the fatigue cracking performances of asphalt mixtures, termed as the three-point bending cylinder (3PBC) test [57]. The novel 3PBC testing configuration adopts the VECD method but does not require any cutting, gluing, or creating a notch in the samples. In addition, it offers some interesting features for pavement design, such as the estimation of Poisson's ration from the test data. Despite the ongoing efforts, many of these techniques are still under investigation, mostly to assess their ability in capturing changes in mix design parameters and variation in results.

The flexural beam fatigue test, suggested by SHRP A-003A, is presently used by several agencies worldwide as a performance test for the asphalt mixtures' fatigue cracking assessment at an intermediate temperature [65-68]. Both constant stress and constant displacement modes can be used to perform FPBB. The constant displacement mode, often known as the constant strain mode, has become the standard form of testing over time. Unlike previous tests, the four point bending test (even referred to as the third point flexure test) was intended to focus on the specimen failure in a domain of uniform bending moment [69]. The advantage of third-point loading over centre-point loading is that the bending moment is constant through the middle third of the specimen; therefore, any weak region owing to non-uniform material qualities will be shown in the test results [70]. FPBB can interpret results using fracture mechanics and dissipated energy techniques to explicitly study the cracking initiation under repeated traffic load. 
Table 1. Correlations between the properties of bitumen from conventional tests and cracking properties of asphalt mixtures from various tests.

\begin{tabular}{|c|c|c|c|c|}
\hline Binder Test/Parameter & Asphalt Mixtures Test/Parameter & $\mathbf{R}^{2}$ & Interpolation & Material Type \\
\hline \multicolumn{5}{|c|}{ Binder Percentage versus Asphalt Mixtures Tests } \\
\hline Binder content $(\%)$ & $\begin{array}{l}\varepsilon^{6} \\
\text { (strain level required for } 1 \mathrm{mil} \text { cycles } \\
\text { fatigue life in FPBB test) } \\
\left.\text { [Testing conditions: } 20^{\circ} \mathrm{C} \& 10 \mathrm{~Hz}\right]\end{array}$ & 0.58 & \multirow{2}{*}[71]{} & \multirow{2}{*}{$\begin{array}{l}\text { - } \quad \text { Conventional } \\
\text { - } \quad \text { Marm Mix Asphalt } \\
\text { and Sasobit: } 4.8 \%, 0.5 \% \text {, and } 1.5 \% \\
\text { by mass of binder, respectively) }\end{array}$} \\
\hline Binder content $(\%)$ & $\begin{array}{c}\mathrm{N}_{100} \\
\text { (Number of cycles }(\mathrm{NoC}) \text { at a strain level of } \\
100 \times 10^{-6} \text { in FPBB test) } \\
\left.\text { [Testing conditions: } 20^{\circ} \mathrm{C} \& 10 \mathrm{~Hz}\right]\end{array}$ & 0.16 & & \\
\hline \multirow{2}{*}{$\begin{array}{c}\text { Asphaltenes }(\%) \text { from } \\
\text { SARA analysis }\end{array}$} & $\begin{array}{l}\text { Material Fatigue Sensitivity (MFS) from } \\
\text { S-VECD test } \\
\left.\text { [Testing conditions: } 18^{\circ} \mathrm{C} \& 10 \mathrm{~Hz}\right]\end{array}$ & 0.50 & \multirow{2}{*}[72]{} & \multirow{2}{*}{$\begin{array}{ll}\text { - } & \text { Conventional } \\
\text { - } & \operatorname{RAP}^{1}\left(20 \% \text { \& } 40 \% \mathrm{RBR}^{2}\right) \\
\text { - } & \operatorname{RAS}^{3}(20 \% \mathrm{RBR})\end{array}$} \\
\hline & $\begin{array}{c}\text { Critical strain energy release rate }\left(\mathrm{J}_{\mathrm{c}}\right) \text { from } \\
\text { SCB test } \\
\left.\text { [Testing conditions: } 25^{\circ} \mathrm{C}\right]\end{array}$ & 0.38 & & \\
\hline
\end{tabular}

RAP $^{1}$ - Reclaimed Asphalt Pavement, RBR $^{2}$ - Reclaimed Binder Ratio- - the percentage of RAP binder by weight with respect to the total binder by weight in the asphalt mix, RAS $^{3}$ - Reclaimed Asphalt Shingles.

Table 2. Correlations between the properties of the bitumen from various miscellaneous tests and cracking properties of asphalt mixtures from various tests.

\begin{tabular}{|c|c|c|c|c|}
\hline Binder Test/Parameter & Asphalt Mixtures Test/Parameter & $\mathbf{R}^{2}$ & Interpolation & Material Type \\
\hline \multicolumn{5}{|c|}{ Binder Miscellaneous Properties vs. Asphalt Mixtures Tests } \\
\hline $\begin{array}{l}\text { Displacement at max } \\
\text { loading from SENB } * \\
\left.\text { [Testing conditions: } 5^{\circ} \mathrm{C}\right]\end{array}$ & $\begin{array}{l}\text { Displacement at max loading from Fénix } \\
\text { test } \\
\left.\text { [Testing conditions: } 5^{\circ} \mathrm{C}\right]\end{array}$ & 0.92 & [73] & $\begin{array}{ll}- & \text { Two neat (PG 64-22 \& PG 76-22) } \\
- & \text { Two modified binders (PG 76-22 } \\
& \text { \& PG 76-28). }\end{array}$ \\
\hline $\begin{array}{c}\text { RTFO ** aged-percent } \\
\text { recovery(\%R) } \\
\text { [ASTM D6084) Method A] } \\
\end{array}$ & \multirow{3}{*}{$\begin{array}{l}\text { CTOD }^{* * * *}(\mathrm{~mm}) \text { from DENT test } \\
{\left[\text { Testing conditions: } 25^{\circ} \mathrm{C}\right]}\end{array}$} & 0.00 & \multirow{3}{*}{ [74] } & \multirow{3}{*}{$\begin{array}{ll}- & \text { PG64-28 (Control) } \\
\text { - } & \text { PG64-28+PPA } \\
\text { - } & \text { PG64-34+SBS } \\
\text { - } & \text { PG76-22+SBS } \\
\text { - } & \text { PG64-22+12\% GTR } \\
\text { PG64-Latex (2\%) }\end{array}$} \\
\hline $\begin{array}{l}\text { \%R from MSCR } * * * \\
\text { Test } \\
\text { [Testing conditions: high } \\
\text { PG temperature of binder } \\
\text { \& stress of } 100 \mathrm{~Pa} \text { ] }\end{array}$ & & 0.41 & & \\
\hline $\begin{array}{c}\mathrm{R} \% \text { from MSCR } \\
\text { Test } \\
\text { [Testing conditions: high } \\
\text { PG temperature of binder } \\
\text { \& stress of } 3200 \mathrm{~Pa} \text { ] }\end{array}$ & & 0.77 & & \\
\hline \multirow{2}{*}{$\begin{array}{c}\text { Critical temperature } \\
\text { difference }\left(\Delta \mathrm{Tc}\left({ }^{\circ} \mathrm{C}\right)\right) \text { from } \\
\text { the BBR test }\end{array}$} & $\begin{array}{c}\mathrm{J}_{\mathrm{C}} \text { from SCB test } \\
\left.\text { [Testing conditions: } 25^{\circ} \mathrm{C}\right]\end{array}$ & 0.77 & \multirow[t]{2}{*}{ [72] } & \multirow{2}{*}{$\begin{array}{ll}- & \text { Conventional } \\
\text { - } & \text { RAP }(20 \% \text { \& } 40 \% \text { RBR }) \\
\text { - } & \text { RAS }(20 \% \text { RBR })\end{array}$} \\
\hline & $\begin{array}{c}\text { MFS from S-VECD test } \\
\left.\text { [Testing conditions: } 18^{\circ} \mathrm{C} \& 10 \mathrm{~Hz}\right]\end{array}$ & 0.57 & & \\
\hline
\end{tabular}

SENB * — single-edge notched beam, RTFO **-Rolling thin film oven, MSCR ***-Multiple stress creep recovery, CTOD ${ }^{* * * *}$-critical tip opening displacement. 
Table 3. Correlations between the properties of the bitumen from time sweep tests and cracking properties of asphalt mixtures from various tests.

\begin{tabular}{|c|c|c|c|c|}
\hline Binder Test/Parameter & Asphalt Mixtures Test/Parameter & $\mathbf{R}^{2}$ & Interpolation & Material Type \\
\hline \multicolumn{5}{|c|}{ Time Sweep vs. Asphalt Mixtures Tests } \\
\hline \multirow{2}{*}{$\begin{array}{l}\text { Cycles to failure }(\mathrm{Np}) \\
\text { [Testing conditions: } 30^{\circ} \mathrm{C} \\
\& 15 \mathrm{~Hz}]\end{array}$} & $\begin{array}{l}\text { Dissipated energy } \\
\text { (N.m) to failure } \\
\text { from IDT } \\
\left.\text { [Testing conditions: } 30^{\circ} \mathrm{C}\right] \\
\end{array}$ & 0.94 & \multirow[t]{2}{*}{ [15] } & \multirow{2}{*}{$\begin{array}{l}\text { - } \quad \text { Conventional }(\mathrm{PG} * 58-22) \\
\text { Crumb rubber }(\mathrm{CR}) \text { modified } \\
\text { asphalt mixtures }(\mathrm{CR} \text { at } 3 \%, 6 \% \text {, } \\
9 \%, 12 \% \text {, and } 15 \% \text { by mass of } \\
\text { binder) }\end{array}$} \\
\hline & $\begin{array}{l}\text { Indirect Tensile Strength (MPa) from IDT } \\
\left.\text { [Testing conditions: } 30^{\circ} \mathrm{C}\right]\end{array}$ & 0.45 & & \\
\hline $\begin{array}{c}\text { NoC at } 50 \% \text { reduction in } \\
\mathrm{G}^{*}[\text { Testing conditions: } \\
24-32^{\circ} \mathrm{C} \& 30 \mathrm{~Hz} \text { to } 0.01 \\
\mathrm{~Hz}]\end{array}$ & $\begin{array}{l}\text { NoC at } 50 \% \text { reduction in } \mathrm{G}^{*} \text { from FPBB test } \\
\left.\text { [Testing conditions: } 24-32{ }^{\circ} \mathrm{C} \& 10 \mathrm{~Hz}\right]\end{array}$ & $\begin{array}{c}0.66- \\
0.90\end{array}$ & [27] & $\begin{array}{ll}- & \text { Conventional } \\
- & \text { Elastomer-modified } \\
-\quad & \text { Oxidised binder (PG 82-22) } \\
-\quad & \text { Plastomer-modified (PG 82-22 \& } \\
& \text { 76-22) }\end{array}$ \\
\hline $\begin{array}{c}\text { Fatigue life }\left(\mathrm{N}_{\mathrm{f}}\right) \\
\text { [Testing conditions: } 20{ }^{\circ} \mathrm{C} \\
\text { \& } 1,5,10 \mathrm{~Hz} \text { ] }\end{array}$ & $\begin{array}{l}\mathrm{N}_{\mathrm{f}} \text { from FPBB test } \\
\left.\text { [Testing conditions: } 20^{\circ} \mathrm{C} \& 10 \mathrm{~Hz}\right]\end{array}$ & 0.98 & [75] & $\begin{array}{ll}\text { - } & \text { Conventional plant-produced } \\
\text { mixture } \\
\text { - } \quad \text { Plant-produced mixture with } \\
\text { 35\% RAP }\end{array}$ \\
\hline $\begin{array}{c}\mathrm{N}_{\mathrm{p} 20} * * \text { at } 5.0 \% \text { strain } \\
\text { [Testing conditions: } \\
12.1^{\circ} \mathrm{C} \\
8.6^{\circ} \mathrm{C} \\
\left.6.2{ }^{\circ} \mathrm{C} \& 10 \mathrm{~Hz}\right]\end{array}$ & $\begin{array}{l}\mathrm{N}_{\mathrm{f}} \text { from FPBB test } \\
\text { [Testing conditions: } \\
12.1^{\circ} \mathrm{C} \\
8.6^{\circ} \mathrm{C} \\
6.2^{\circ} \mathrm{C} \& 10 \mathrm{~Hz} \text { ] }\end{array}$ & $\begin{array}{c}0.31- \\
0.54\end{array}$ & [76] & $\begin{array}{ll}\text { - } & \text { PG 64-28 (Styrene-Butadiene } \\
\text { - } & \text { Styrene Rubber) } \\
\text { - } & \text { PG 64-34 (Ethylene Ter-polymer) (Ethylene Ter-polymer) }\end{array}$ \\
\hline Stiffness Modulus $\left(G^{*}\right)$ & $\mathrm{N}_{\mathrm{f}}$ from FPBB test (AASHTO T321) & 0.04 & [77] & $\begin{array}{l}\text { - } \quad \text { Mixtures with } 25 \% \text { and } 50 \% \text { RAP } \\
\text { Mixtures with } 25 \% \text { and } 50 \% \text { RAP } \\
\text { along with rejuvenator (7.5\% by } \\
\text { mass of the recycled asphalt } \\
\text { binder) }\end{array}$ \\
\hline
\end{tabular}

PG *-Performance Grade, $\mathrm{N}_{\mathrm{p} 20}{ }^{* *}-\mathrm{NoC}$ when the dissipated energy ratio detracts 20 percent from the equality line.

Table 4. Correlations between the properties of the bitumen from frequency sweep tests and cracking properties of asphalt mixtures from various tests.

\begin{tabular}{|c|c|c|c|c|}
\hline Binder Test/Parameter & Asphalt Mixtures Test/Parameter & $\mathbf{R}^{2}$ & Interpolation & Material Type \\
\hline \multicolumn{5}{|c|}{ G*.Sin ${ }^{*}$ from Frequency Sweep Test vs. Asphalt Mixtures Tests } \\
\hline \multirow{2}{*}{$\begin{array}{c}\mathrm{G}^{*} \cdot \operatorname{Sin} \delta \\
{\left[\text { Testing conditions: } 30^{\circ} \mathrm{C}\right]}\end{array}$} & $\begin{array}{l}\text { Dissipated Energy }(\mathrm{N} \cdot \mathrm{m}) \text { to failure from } \\
\text { IDT } \\
\left.\text { [Testing conditions: } 30^{\circ} \mathrm{C}\right]\end{array}$ & 0.68 & \multirow[t]{2}{*}{ [15] } & \multirow{2}{*}{$\begin{array}{l}\text { - Conventional (PG 58-22) } \\
\text { Crumb rubber (CR) modified } \\
\text { asphalt mixtures (CR at } 3 \%, 6 \% \text {, } \\
9 \%, 12 \% \text {, and } 15 \% \text { by mass of } \\
\text { binder) }\end{array}$} \\
\hline & $\begin{array}{c}\text { Indirect Tensile Test Strength (MPa) from } \\
\text { IDT } \\
\left.\text { [Testing conditions: } 30^{\circ} \mathrm{C}\right]\end{array}$ & 0.90 & & \\
\hline $\begin{array}{l}\mathrm{G}^{*} \operatorname{Sin} \delta \\
\text { [Testing conditions: } 24-32 \\
\left.{ }^{\circ} \mathrm{C} \& 15^{\circ} \mathrm{C}\right]\end{array}$ & $\begin{array}{l}\mathrm{N}_{\mathrm{f}} \text { from FPBB test } \\
\left.\text { [Testing conditions: } 24-32{ }^{\circ} \mathrm{C} \& 10 \mathrm{~Hz}\right]\end{array}$ & 0.23 & [27] & $\begin{array}{ll}- & \text { Conventional } \\
- & \text { Elastomer-modified } \\
- & \text { Oxidised binder (PG 82-22) } \\
\text { - } & \text { Plastomer-modified (PG 82-22 \& } \\
& \text { 76-22) }\end{array}$ \\
\hline \multirow{2}{*}{$\begin{array}{c}\mathrm{G}^{*} \operatorname{Sin} \delta \\
\left.\text { [Testing conditions: } 25^{\circ} \mathrm{C}\right]\end{array}$} & $\begin{array}{c}\mathrm{N}_{\mathrm{f}} \text { from FPBB test } \\
\left.\text { [Testing conditions: } 25^{\circ} \mathrm{C} \& 10 \mathrm{~Hz}\right]\end{array}$ & 0.60 & \multirow[t]{2}{*}{ [78] } & \multirow{2}{*}{$\begin{array}{l}\text { - PG 58-22 and PG 64-22 } \\
\text { Mixtures of PG 58-22 and PG } \\
\text { 64-22 modified with } 4 \%, 8 \% \text {, and } \\
12 \% \text { gilsonite, and 3\% and 5\% } \\
\text { SBS (by mass of binder) }\end{array}$} \\
\hline & $\begin{array}{l}\mathrm{RDEC}^{* *} \text { from FPBB test } \\
\left.\text { [Testing conditions: } 25^{\circ} \mathrm{C} \& 10 \mathrm{~Hz}\right]\end{array}$ & 0.59 & & \\
\hline
\end{tabular}


Table 5. Correlations between the properties of the bitumen from LAS tests and cracking properties of asphalt mixtures from various tests.

\begin{tabular}{|c|c|c|c|c|}
\hline Binder test/Parameter & Asphalt Mixtures Test/Parameter & $R^{2}$ & Interpolation & Material Type \\
\hline \multicolumn{5}{|c|}{ LAS vs. Asphalt Mixtures Tests } \\
\hline $\begin{array}{l}\text { NoC to failure } \\
\text { [Testing conditions: } \\
\text { intermediate PG } \\
\text { temperature] }\end{array}$ & $\begin{array}{c}\text { Ratio between LTPP * Cracked Area \& } \\
\text { Pavement Thickness } \\
\text { [Testing conditions: intermediate PG } \\
\text { temperature] }\end{array}$ & 0.64 & [38] & Eight LTPP binders \\
\hline $\begin{array}{c}\text { Damage parameter } \\
\text { determined using VECD } \\
\text { analysis of strain sweep } \\
\text { data at } 25 \% \text { reduction in } \\
\mathrm{G}^{*} \\
\text { [Testing conditions: } 12.1 \\
{ }^{\circ} \mathrm{C} \\
8.6^{\circ} \mathrm{C} \\
6.2{ }^{\circ} \mathrm{C} \& 10 \mathrm{~Hz} \text { ] }\end{array}$ & $\begin{array}{c}\mathrm{N}_{\mathrm{f}} \text { from FPBB test } \\
\text { [Testing conditions: } 12.1^{\circ} \mathrm{C} \\
8.6^{\circ} \mathrm{C} \\
\left.6.2{ }^{\circ} \mathrm{C} \& 10 \mathrm{~Hz}\right]\end{array}$ & $\begin{array}{l}0.98- \\
0.99\end{array}$ & [76] & $\begin{array}{ll}\text { - } & \text { PG 64-28 (Styrene-Butadiene Styrene } \\
\text { - } & \text { Rubber) } \\
\text { - } & \text { PG 58-34 (Ethylene Ter-polymer) } \\
& \end{array}$ \\
\hline $\begin{array}{l}\mathrm{A}_{35} \text { value (fatigue life of } \\
\text { binder expressed as } \\
\text { number of cycles) } \\
\left.\text { [Testing conditions: } 20^{\circ} \mathrm{C}\right]\end{array}$ & \multirow[t]{2}{*}{$\begin{array}{c}\mathrm{N}_{\mathrm{f}} \text { from FPBB test } \\
\left.\text { [Testing conditions: } 20^{\circ} \mathrm{C} \& 10 \mathrm{~Hz}\right]\end{array}$} & $\begin{array}{l}0.85- \\
0.96\end{array}$ & \multirow[t]{2}{*}{ [79] } & \multirow{2}{*}{$\begin{array}{ll}- & \text { Conventional } \\
- & \text { Mixture modified with } 6 \% \mathrm{LDPE} \\
\text { - } & \text { Mixtures with nano clay additives at } 3 \\
\text { different percentages }\end{array}$} \\
\hline $\begin{array}{l}\text { Cumulative dissipated } \\
\text { energy } \\
\left.\text { [Testing conditions: } 20^{\circ} \mathrm{C}\right]\end{array}$ & & $\begin{array}{l}0.92- \\
0.95\end{array}$ & & \\
\hline $\begin{array}{l}\text { Predicted Binder Fatigue } \\
\text { life using S-VECD model } \\
\left.\text { [Testing conditions: } 18^{\circ} \mathrm{C}\right]\end{array}$ & $\begin{array}{l}\text { Field } \mathrm{N}_{\mathrm{f}} @ 25 \text { metres }(\mathrm{m}) \text { cracking } \\
\text { formulation from } \\
\text { FHWA **-ALF ***[Testing conditions: } 18 \\
\left.{ }^{\circ} \mathrm{C}\right]\end{array}$ & 0.98 & [80] & $\begin{array}{ll}- & \text { PG 64-22 } \\
- & \text { PG 64-22 STA } \\
- & \text { PG 64-22 LTA } \\
- & \text { CR-TB } \\
- & \text { Terpolymer } \\
- & \text { SBS-LG }\end{array}$ \\
\hline $\begin{array}{l}\text { Binder Fatigue life } \\
\text { coupled with S-VECD } \\
\text { analysis } \\
\left.\text { [Testing conditions: } 19^{\circ} \mathrm{C}\right]\end{array}$ & $\begin{array}{l}\text { Fatigue life from controlled crosshead } \\
\text { (CX) cyclic direct tension tests } \\
\left.\text { [Testing conditions: } 19^{\circ} \mathrm{C}\right]\end{array}$ & 0.84 & [81] & $\begin{array}{ll}\text { - } & \text { PG 70-22 } \\
\text { - } & \text { Mixtures modified with Evotherm 3G } \\
\text { (0.5\% by weight of total asphalt }) \\
\text { - } \\
\text { Mixtures modified with foaming additive } \\
(0.7 \% \text { by weight of total asphalt })\end{array}$ \\
\hline $\begin{array}{l}\text { LAS-'A' parameter } \\
\left.\text { [Testing conditions: } 19^{\circ} \mathrm{C}\right]\end{array}$ & $\begin{array}{l}\text { Fatigue cracking from LTPP } \\
\text { measurements } \\
\left.\text { [Testing conditions: } 19^{\circ} \mathrm{C}\right]\end{array}$ & 0.93 & [82] & $\begin{array}{ll}\text { - } & \text { PG 64-28 } \\
\text { - } & \text { PG 64-28-sbs } \\
\text { - } & \text { PG 64-34 Elvaloy } \\
& \text {-34 Elvaloy }\end{array}$ \\
\hline $\begin{array}{l}\text { LAS-'A' parameter } \\
\text { [Testing conditions: } \\
\text { intermediate PG } \\
\text { temperature] }\end{array}$ & \multirow[t]{4}{*}{$\begin{array}{l}\text { CTOD }^{* * * *}(\mathrm{~mm}) \text { from DENT test } \\
\left.\text { [Testing conditions: } 25^{\circ} \mathrm{C}\right]\end{array}$} & 0.00 & [74] & \multirow{4}{*}{$\begin{array}{ll}- & \text { PG64-28 (Control) } \\
- & \text { PG64-28+PPA } \\
\text { - } & \text { PG64-34+SBS } \\
\text { - } & \text { PG76-22+SBS } \\
& \text { PG64-22+12\% GTR } \\
& \text { PG64-28+Latex (2\%) }\end{array}$} \\
\hline $\begin{array}{l}\text { LAS-'B' parameter } \\
\text { [Testing conditions: } \\
\text { intermediate PG } \\
\text { temperature] }\end{array}$ & & 0.32 & & \\
\hline $\begin{array}{l}\mathrm{N}_{\mathrm{f} @ 2.5 \% \text { strain }} \\
\text { [Testing conditions: } \\
\text { intermediate PG } \\
\text { temperature] }\end{array}$ & & 0.48 & & \\
\hline $\begin{array}{l}\mathrm{N}_{\mathrm{f}} @ 5 \% \text { strain } \\
\text { [Testing conditions: } \\
\text { intermediate PG } \\
\text { temperature] }\end{array}$ & & 0.66 & & \\
\hline
\end{tabular}


Table 5. Cont.

\begin{tabular}{|c|c|c|c|c|}
\hline Binder test/Parameter & Asphalt Mixtures Test/Parameter & $\mathbf{R}^{2}$ & Interpolation & Material Type \\
\hline $\mathrm{N}_{\mathrm{f} @}$ & $\begin{array}{c}\mathrm{N}_{\mathrm{f}} \text { from FPBB test } \\
\left.\text { [Testing conditions: } 25^{\circ} \mathrm{C} \& 10 \mathrm{~Hz}\right]\end{array}$ & 0.94 & \multirow{4}{*}{ [78] } & \multirow{4}{*}{$\begin{array}{l}\text { - } \quad \text { PG } 58-22 \text { and PG } 64-22 \\
\text { Mixtures of PG 58-22 and PG } 64-22 \\
\text { modified with } 4 \%, 8 \% \text {, and } 12 \% \text { gilsonite, } \\
\text { and } 3 \% \text { and } 5 \% \text { SBS (by mass of binder) }\end{array}$} \\
\hline $\begin{array}{c}3,4,5 \% \text { strain } \\
\left.\text { [Testing conditions: } 25^{\circ} \mathrm{C}\right]\end{array}$ & $\begin{array}{c}\text { RDEC from FPBB test } \\
\left.\text { [Testing conditions: } 25^{\circ} \mathrm{C} \& 10 \mathrm{~Hz}\right]\end{array}$ & 0.95 & & \\
\hline $\begin{array}{c}\text { LAS-'A' parameter } \\
\left.\text { [Testing conditions: } 25^{\circ} \mathrm{C}\right]\end{array}$ & $\begin{array}{c}\mathrm{N}_{\mathrm{f}} \text { from FPBB test } \\
\left.\text { [Testing conditions: } 25^{\circ} \mathrm{C} \& 10 \mathrm{~Hz}\right]\end{array}$ & 0.86 & & \\
\hline $\begin{array}{c}\text { LAS-'A' parameter } \\
\left.\text { [Testing conditions: } 25^{\circ} \mathrm{C}\right]\end{array}$ & $\begin{array}{c}\text { RDEC from FPBB test } \\
\left.\text { [Testing conditions: } 25^{\circ} \mathrm{C} \& 10 \mathrm{~Hz}\right]\end{array}$ & 0.90 & & \\
\hline $\mathrm{N}_{\mathrm{f}} @ 2.5,3.5$ and $4 \%$ strain & $\mathrm{N}_{\mathrm{f}}$ from FPBB test@500, 700, $800 \mu$ strain & 0.87 & \multirow{2}{*}{ [77] } & \multirow{2}{*}{$\begin{array}{l}\text { - } \quad \text { Mixtures with } 25 \% \text { and } 50 \% \text { RAP } \\
\text { Mixtures with } 25 \% \text { and } 50 \% \text { RAP along } \\
\text { with rejuvenator ( } 7.5 \% \text { by mass of the } \\
\text { recycled asphalt binder) }\end{array}$} \\
\hline $\mathrm{N}_{\mathrm{f}} @ 2.5 \%$ strain & IDT fatigue testing (ITFT) & 0.93 & & \\
\hline \multirow{2}{*}{$\begin{array}{c}\mathrm{N}_{\mathrm{f}} \\
\left.\text { [Testing conditions: } 25^{\circ} \mathrm{C}\right]\end{array}$} & \multirow{2}{*}{$\begin{array}{c}\mathrm{N}_{\mathrm{f}} \text { from FPBB test } \\
\left.\text { [Testing conditions: } 25^{\circ} \mathrm{C}\right]\end{array}$} & 0.99 & \multirow{2}{*}{ [75] } & \multirow{2}{*}{$\begin{array}{ll}\text { - } & \text { Conventional plant-produced mixture } \\
\text { - } & \text { Plant-produced mixture with } 35 \% \text { RAP } \\
\end{array}$} \\
\hline & & 0.95 & & \\
\hline $\begin{array}{c}\mathrm{N}_{\mathrm{f}} \\
\left.\text { [Testing conditions: } 20^{\circ} \mathrm{C}\right]\end{array}$ & $\begin{array}{c}\mathrm{N}_{\mathrm{f}} \text { from FPBB test } \\
\left.\text { [Testing conditions: } 20^{\circ} \mathrm{C}\right]\end{array}$ & 0.99 & [83] & $\begin{array}{ll}- & \text { VG } 10 \text { and VG } 30 \\
- & \text { Mixtures modified with EVA and SBS }\end{array}$ \\
\hline $\begin{array}{l}\mathrm{N}_{\mathrm{f}} \\
{\left[\text { Testing conditions: } 20^{\circ} \mathrm{C}\right]}\end{array}$ & $\begin{array}{c}\mathrm{N}_{\mathrm{f}} \text { from FPBB test } \\
\left.\text { [Testing conditions: } 20^{\circ} \mathrm{C}\right]\end{array}$ & 0.99 & [6] & $\begin{array}{l}\text { - } \quad \text { Mixtures with neat } 30 / 45 \text { binder } \\
\text { Mixtures with } 3.0 \% \text { and } 7.5 \% \text { SBS } \\
\text { modified binder }\end{array}$ \\
\hline $\begin{array}{c}\mathrm{N}_{\mathrm{f}} \\
\left.\text { [Testing conditions: } 20^{\circ} \mathrm{C}\right]\end{array}$ & $\begin{array}{l}\mathrm{N}_{\mathrm{f}} \text { fromITFT test [Testing conditions: } 20 \\
\left.{ }^{\circ} \mathrm{C}\right]\end{array}$ & $\begin{array}{l}0.37- \\
0.98\end{array}$ & [84] & $\begin{array}{ll}\text { - } & \text { Control } \\
\text { Mixtures modified with } 3 \%, 6 \% \text {, and } 9 \% \\
\text { - } \\
\text { - } \\
\text { Miliceous additives modified with } 3 \%, 6 \% \text {, and } 9 \% \\
\text { date seed ash (DSA) } \\
\text { - Mixtures modified with } 3 \%, 6 \% \text {, and 9\% } \\
\text { limestone }\end{array}$ \\
\hline $\begin{array}{c}\mathrm{A}_{35} \\
\left.\text { [Testing conditions: } 20^{\circ} \mathrm{C}\right]\end{array}$ & $\begin{array}{l}\mathrm{N}_{\mathrm{f}} \text { from FPBB test } \\
\left.\text { [Testing conditions: } 20^{\circ} \mathrm{C}\right]\end{array}$ & 0.68 & [10] & $\begin{array}{ll}- & \text { Conventional } \\
- & \text { RAP (20\% \& } 40 \% \text { RBR }) \\
- & \text { RAS (20\% RBR) } \\
\text { - } & \text { RAS \& RAP mixtures modified with } \\
& \text { Evotherm and water foam technologies }\end{array}$ \\
\hline $\begin{array}{c}\mathrm{A}_{35} \\
\left.\text { [Testing conditions: } 20^{\circ} \mathrm{C}\right]\end{array}$ & $\begin{array}{l}\mathrm{N}_{\mathrm{f}} \text { from FPBB test } \\
\left.\text { [Testing conditions: } 20^{\circ} \mathrm{C}\right]\end{array}$ & 0.863 & [85] & $\begin{array}{l}\text { - } \quad \text { AC- } 60 / 70 \\
\text { Mixtures modified with 2, 4, 6, and } 8 \\
\text { percent of nano silica }\end{array}$ \\
\hline
\end{tabular}

LTPP *-long-term pavement performance, FHWA **_Federal Highway Administration, ALF ***-Accelerated Loading Facility, CTOD ****_critical tip opening displacement.

A comprehensive literature review was conducted to cover the correlation between bitumen and asphalt mixtures, testing parameters in the form of the Pearson correlation coefficient $\left(\mathrm{R}^{2}\right.$, the proportion of the variation in the dependent variable that is predictable from the independent variable) and considering various tests at different conditions (Tables 1-5). Information on the testing and material types has also been reported in these tables.

In Table 1 , the binder and its fraction percentage were correlated with various parameters of asphalt mixtures. The correlation of the binder content (\%) and asphaltenes (\%) from a Saturate, Aromatic, Resin and Asphaltene (SARA) analysis with the various asphalt mixtures' test parameters found in the literature was weak to moderate. Similarly, Table 2 shows that various miscellaneous tests (not necessarily related to cracking) conducted on binders were correlated with cracking parameters of asphalt mixtures. The strength of the correlation was variable (weak, moderate, and strong) depending on the particular study considered. 
In Table 3, rheological parameters from the time sweep test on binders were correlated with various cracking parameters of asphalt mixtures tests. The strength of the correlation was found as moderate to strong, whereas only a few studies reported a weak to moderate correlation.

In Table 4, the SHRP fatigue cracking parameter from frequency sweep tests on binders was correlated with various cracking parameters from asphalt mixture tests. The correlation was found moderate to strong except in one study where it was found weak.

Table 5 shows the correlation between parameters from the LAS test on binders with various cracking parameters of asphalt mixture tests. Correlation was found moderate to very strong except on a few studies where it was weak to moderate.

The previous Tables 1-5 show that bitumen tests used to determine fatigue properties and asphalt mixture tests have varying degrees of correlation. Conventional bitumen tests have limited significance in predicting the asphalt mixture's fatigue properties. The SHRP fatigue rheological parameter is only limited to the analysis of linear viscoelastic behaviour under small deformations - one of the primary justifications for the poor correlation, especially for polymer-modified bitumen (PMB). The time-sweep test demonstrated a significant correlation with the fatigue characteristics of asphalt mixes. However, given the uncertainty in the testing period and reduced testing repeatability, the time sweep test is not a feasible approach for specifying asphalt binder fatigue resistance [38].

Although only a few studies showed a significant correlation between asphalt and binder tests, others found little to none; this was primarily dependent on bitumen content, polymer types used in modification, aggregate gradation, testing technique, and loading and environmental conditions utilised in the research studies. The usage of emerging polymer-modified bituminous binders (highly modified, plastomer-modified, hybridmodified, modified with recycled material) may contribute to this variability; therefore, additional research is needed to correlate bitumen and asphalt intermediate temperature performance. There is currently limited data or correlations comparing binders and asphalt mixes made from plastomers, elastomers, polymeric compounds with fibres, and amino-wax-based additives. Furthermore, the existing literature shows no direct association between binder fatigue life determined by the LAS method and asphalt cracking determined through IDT, SCB, and FPBB tests. The present study evaluates a variety of polymer-modified binders and their performance in asphalt mixes.

The main goal of this study is to determine the statistical correlation between fatigue cracking parameters of different asphalt binders as measured by the LAS parameters and the cracking resistance of asphalt mixes produced with the same binders and tested using IDT, SCB, and FPBB techniques. Various polymer-modified binders were tested under varied testing conditions to determine the correlation between bitumen and asphalt tests (i.e., temperature and stress level).

\section{Materials and Methods}

This research used one neat bitumen and five different polymer-modified binders to examine the correlation between the binders and their respective asphalt mixtures. These polymers are comprised of plastomers ( $6 \%$ by weight of the binder), elastomers (approximately $6 \%$ by weight of the binder), polymeric compounds of elastomer and micro-cellulose fibre $(0.3 \%$ by weight of the aggregate), polymeric compounds of plastomers/elastomers and micro-cellulose fibre $(0.3 \%$ by weight of the aggregate), and amino-wax based additives $(0.3 \%$ by weight of the binder) used in bitumen modification that reduces mixing and the compaction temperature of asphalt mixtures. Table 6 outlines the material characteristics and the methodology used for blending various polymer binders and corresponding mixtures in this research study. The dosages of various polymers/additives and their mixing and compaction conditions were selected based on the manufacturer's recommendations and previous outcomes from literature studies on similar types of products and mixes. It should be noted that this research aimed to study the correlation between various tests looking at the cracking properties of bitumen and asphalt mixtures for a wide range of 
blends rather than to assess their relative performance. Hence, the different polymer content among the various mixes does not affect the main scope of the analysis but rather enhances the variability among samples to possibly ascertain greater statistical significance when looking at the correlation between tests.

Table 6. Types of material.

\begin{tabular}{|c|c|c|c|c|}
\hline $\begin{array}{l}\text { Name of Poly- } \\
\text { mers/Additives }\end{array}$ & $\begin{array}{l}\text { Nomenclature } \\
\text { Used in This } \\
\text { Study }\end{array}$ & $\begin{array}{c}\text { Type of } \\
\text { Polymers/Additives [4] }\end{array}$ & $\begin{array}{c}\text { Percentage of } \\
\text { Polymers/Additives }\end{array}$ & Method of Blending [4] \\
\hline $\begin{array}{c}\text { Amino-Wax } \\
\text { Based Additives }\end{array}$ & - & $\begin{array}{c}\text { Amino derivatives in } \\
\text { liquid form; Density } \\
\left(25^{\circ} \mathrm{C}\right)=0.95-1.05 \mathrm{~g} / \mathrm{cm}^{3} \\
\text { Viscosity }\left(25^{\circ} \mathrm{C}\right)= \\
150-250 \mathrm{cP}\end{array}$ & $\begin{array}{l}0.3 \% \text { by weight of neat } \\
\text { bitumen }(\mathrm{C} 320)\end{array}$ & $\begin{array}{l}\text { - } \\
\text { beating of aggregates }\left(145^{\circ} \mathrm{C}\right) \text { and } \\
\text { bitumen }\left(140^{\circ} \mathrm{C}\right) \\
\text { Addition of additives in bitumen }+ \\
\text { blending for } 20 \text { min using a shear mixer } \\
\text { Pouring modified bitumen into } \\
\text { aggregates }+ \text { mixing at } 140{ }^{\circ} \mathrm{C}(5 \mathrm{~min}) \\
\text { Addition of filler into aggregates }+ \\
\text { mixing at } 140^{\circ} \mathrm{C} \text { for } 10 \text { min }\end{array}$ \\
\hline Plastomer-Fibres & \multirow[t]{2}{*}{ Fibres Family } & $\begin{array}{l}\text { Proprietary blend (pellet } \\
\text { form) of cellulose/glass } \\
\text { fibres and plastomeric (PE) } \\
\text { polymers }\end{array}$ & \multirow[t]{2}{*}{$\begin{array}{l}0.3 \% \text { by weight of } \\
\text { aggregates }\end{array}$} & \multirow{3}{*}{ 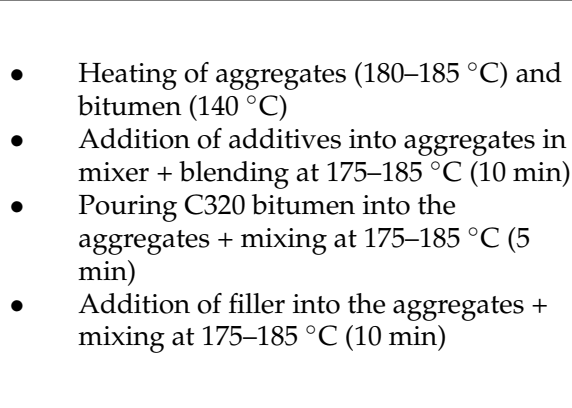 } \\
\hline Elastomer-Fibre & & $\begin{array}{l}\text { Proprietary blend (pellet } \\
\text { form) of cellulose fibres } \\
\text { and elastomeric polymers } \\
\text { (SBS.) }\end{array}$ & & \\
\hline Plastomers & Plastomers & $\begin{array}{l}\text { A compound of } \\
\text { polyethylene-based } \\
\text { plastomers }\end{array}$ & $\begin{array}{l}6 \% \text { by weight of neat } \\
\text { bitumen }(\mathrm{C} 320)\end{array}$ & \\
\hline $\begin{array}{l}\text { Commercially } \\
\text { available } \\
\text { SBS-modified } \\
\text { bitumen }\end{array}$ & Elastomers & $\begin{array}{c}\text { Styrene-butadiene- } \\
\text { styrene (SBS); 70:30 } \\
\text { styrene/butadiene ration } \\
\text { (linear) }\end{array}$ & $\begin{array}{l}\text { Industrially modified with } \\
\text { approx. } 6 \% \text { of SBS (by } \\
\text { weight of binder) }\end{array}$ & 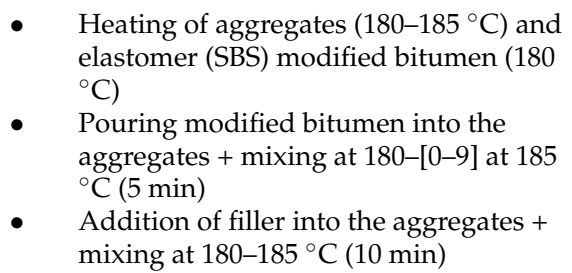 \\
\hline
\end{tabular}

Cylindrical IDT and SCB samples and prismatic beam-like samples were compacted to achieve $5 \pm 0.5 \%$ air voids. Asphalt mixtures were manufactured at $5 \%$ bitumen content (by weight of the mix).

The mixed aggregate gradation is shown in Figure 1 and reflects the proportion identified by Australian standards [86] for an intermediate asphalt layer. 


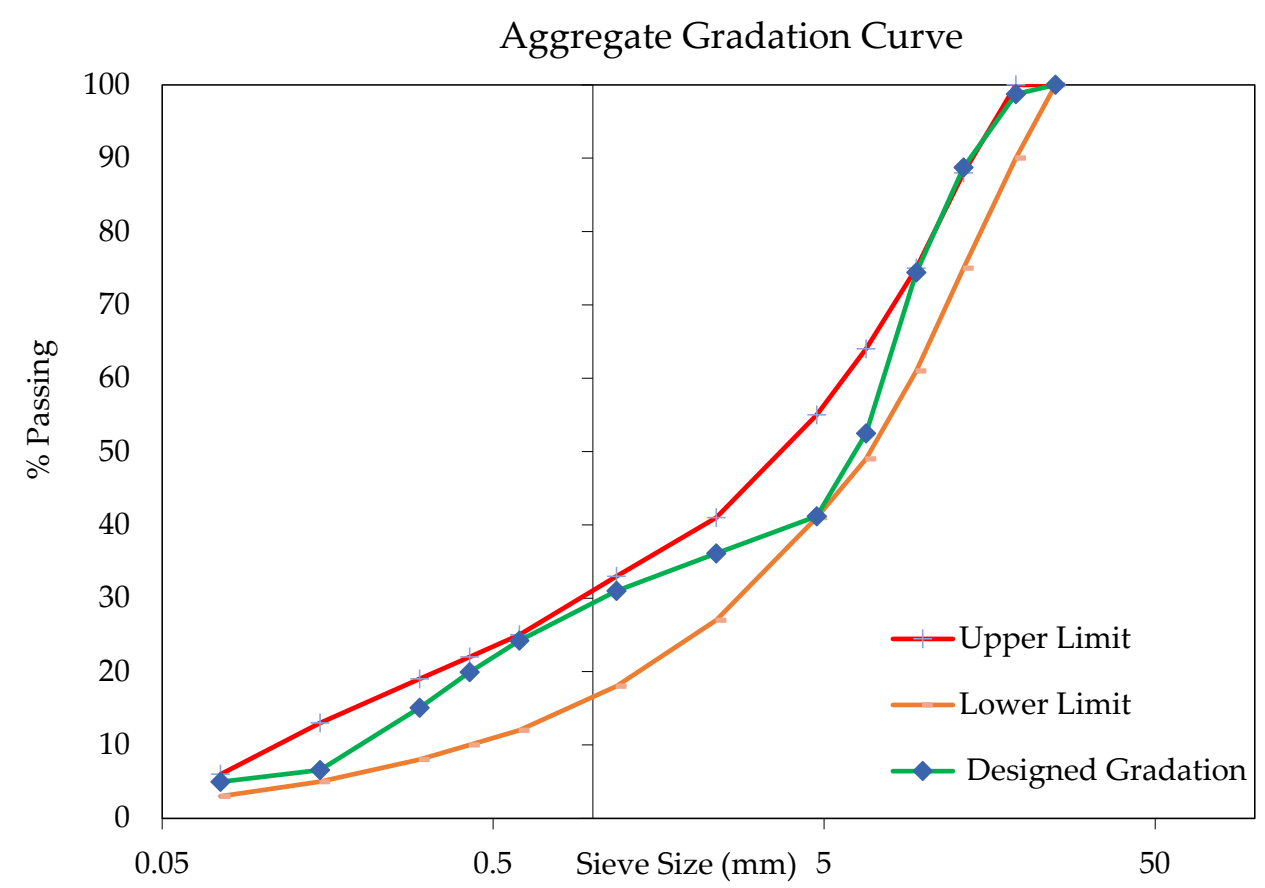

Figure 1. Combined aggregate gradation curve of the asphalt mixtures.

\section{Experimental Plan}

A total of four different types of testing, one on the binder and three on the asphalt mixtures, were conducted in this research. The methodology followed to develop the correlation among the cracking properties of the various binders, and their corresponding asphalt mixtures is given in Figure 2. The research was further divided into two major parts. Phase 1 investigated the fatigue performance of the binders via the LAS test (AASHTO T 391), which considers a 35\% reduction in the initial modulus. The number of cycles to failure was evaluated at two different strain levels $(2.5 \%$ and $5 \%)$ in the LAS test. Phase 2 assessed the cracking initiation and propagation potential of asphalt mixtures produced using the LAS test's respective binders. Three different types of tests, namely, IDT, SCB, and FPBB, were carried out.

Apart from the interest in determining how bituminous binders' cracking properties may aid in the accurate prediction of the cracking potential of asphalt mixes at an intermediate temperature, this study was unique in that it investigated how different types of blends (plastomers, elastomers, polymeric compounds with fibres, amino-wax based additives, and unmodified bitumen) expressed the bitumen-asphalt correlation under varied testing conditions (i.e., loading rate and loading modes). Blends were further grouped based on blend composition and diversity of materials to investigate how this affected the correlation; for example, the "PMB family" includes all blends made up from various polymers (plastomers, elastomers, and polymeric compounds with microfibres). The most comprehensive group was "All-Sources" that includes all modified blends (four polymer-modified blends + one modified blend with an additive) and a blend without modification.

\subsection{Linear Amplitude Sweep (LAS) Test}

The LAS test comprises an initial frequency sweep test followed by the amplitude sweep test [38,82]. A frequency sweep test with a strain amplitude of $0.1 \%$ and frequency range from $0.1 \mathrm{~Hz}$ to $30 \mathrm{~Hz}$ was performed according to AASHTO T 391 to obtain the undamaged material characteristics and fatigue law parameter $(\alpha)$ [87]. The second part of the test was then carried out in oscillatory shear mode at a constant frequency of $10 \mathrm{~Hz}$ and $25{ }^{\circ} \mathrm{C}$. Strain was increased linearly from $0.1 \%$ to $30 \%$ throughout 3100 cycles of loading, for a total test time of $310 \mathrm{~s}$. Three replicates were tested at each testing condition. The 
viscoelastic continuum damage (VECD) mechanics model [88] was used to compute the A and B parameters of the fatigue law (Equation (1)). In the LAS test, failure criteria are defined as a $35 \%$ decrease of the initial modulus of the binder.

$$
N_{f}=A_{35}\left(\gamma_{\max }\right)^{-B}
$$

where:

$A$ and $B$ : Parameters of the VECD model associated with the material property $N_{f}$ : Fatigue failure life

$\gamma_{\max }$ : Maximum shear strain for the given pavement structure

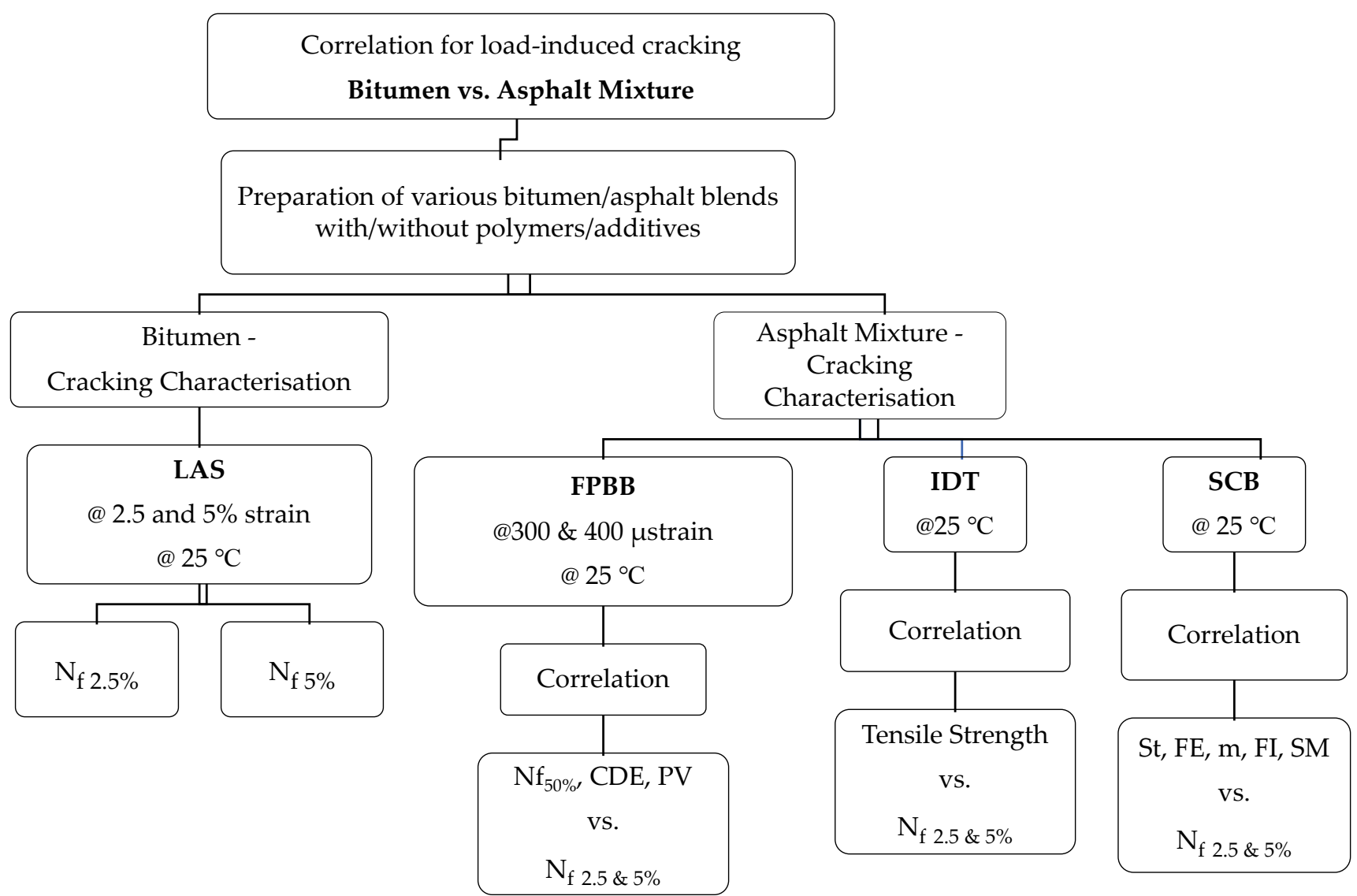

Figure 2. Experimental plan.

\subsection{Indirect Tensile (IDT) Test}

A cylindrical specimen was constantly compressed at 50 millimetres per minute during an indirect tensile test until it failed. A gyratory compactor was used to fabricate specimens with a diameter of $100 \mathrm{~mm}$ and a thickness of $65 \mathrm{~mm}$, with air voids of $5 \pm 0.5 \%$. The test was conducted at $25^{\circ} \mathrm{C}$ according to ASTM D6931-17, and three replicates for each asphalt mix were tested. The failure strength (ITS) was calculated using Equation (2).

$$
\operatorname{ITS}(S t)=\frac{2000 P}{\pi D t} .
$$

where ITS $=$ Indirect Tensile Strength $(\mathrm{kPa}), P=$ maximum load $(\mathrm{N}), t=$ thickness of specimen $(\mathrm{mm})$, and $D=$ diameter of specimen $(\mathrm{mm})$. 


\subsection{Semi-Circular Bending (SCB) Test}

The Illinois Flexibility Index Test (I-FIT procedure), also referred to as Illinois SCB (IL-SCB), was performed at an intermediate temperature of $25^{\circ} \mathrm{C}$ according to AASHTO TP-124 [89]. A three-point bending loading setup was used to apply tensile stresses to a half-cylindrical test specimen $(150 \mathrm{~mm} \times 50 \mathrm{~mm}$ in diameter and thickness, compacted at air voids of $5 \pm 0.5 \%$ ) with a notch in the centre. The sample was loaded with a $50 \mathrm{~mm} / \mathrm{min}$ constant deformation rate until failure [43,90,91]. The flexibility index (FI), fracture energy (FE), fracture strength $(\mathrm{St})$, slope $(\mathrm{m})$, and secant modulus (s.m) were the primary outcomes of the test method. Three samples for each material were tested under similar environmental and loading conditions.

\section{Data Analysis Technique}

The load-displacement curves for the six studied mixes are shown in Figure 3. It is interesting to observe that various materials exhibited different behaviours before and after the failure of the specimen. Less stiff and more elastic mixtures (elastomers, amino wax-additives) exhibited ductile behaviour and showed the lowest pre- and post-slope values compared to stiffer mixtures (plastomers, compound of microfibres and polymers). However, the force required to bring the sample to failure in the first subset of mixtures was relatively lower compared to the latter group. Time of loading (displacement) and maximum load are equally important while studying the cracking performance at an intermediate temperature. Therefore, the concept of calculating the total work (fracture energy) is essential to explain the combined effect of the rate of failure and the maximum force required at the time of failure. This type of illustration is helpful to provide a more reliable picture of crack initiation potential in real traffic conditions.

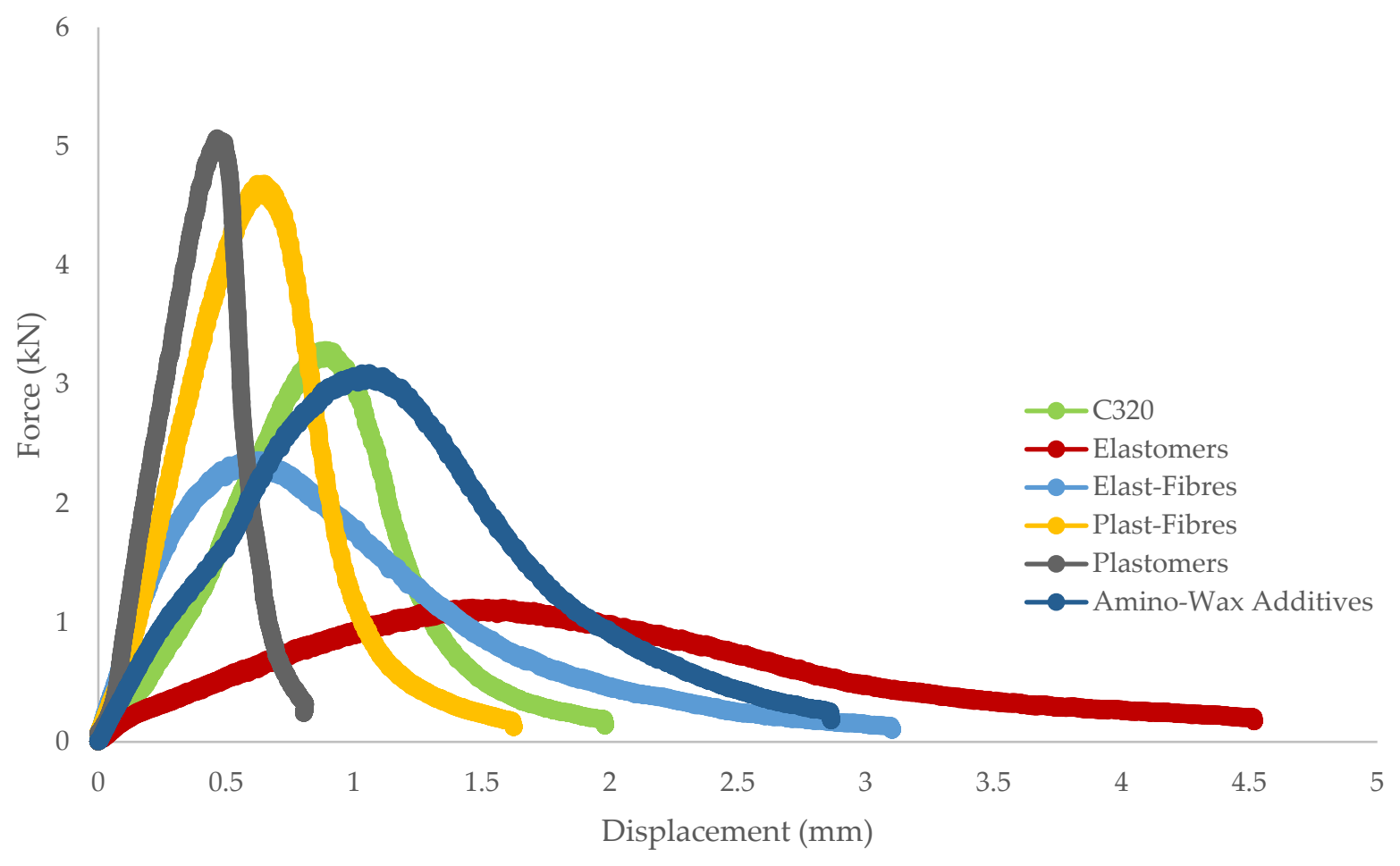

Figure 3. Typical load-displacement curves for various mixes.

The fracture energy was determined to quantify the cracking resistance of AC mixtures. The fracture work method defines fracture energy as the area under load-displacement curves until the specimen is fractured [92,93]. This work will equate to fracture energy if all the work is utilised by crack development and propagation. This technique estimates fracture energy, or more precisely, apparent fracture energy. The calculation of the apparent 
fracture energy assumes that all the work is being utilised by the crack development and propagation, although this is not always the case, as there are few mechanical and heat losses during testing. The mathematical function is shown as follows:

$$
G_{f a}=\frac{1}{b(D-a)}\left[\int_{0}^{\mu_{0}} P_{1}(\mu) d \mu+\int_{\mu_{0}}^{\mu_{\text {final }}} P_{2}(\mu) d \mu\right]
$$

where $b=$ specimen thickness, $D=$ diameter of the specimen, and $a=$ width of the notch.

$P_{1}(\mu)$ and $P_{2}(\mu)=$ fitting equations before and after the peak, respectively.

$\mu_{0}=$ displacement at the peak.

$\mu_{\text {final }}=$ final displacement that can be selected as the displacement at a cut-off load value where the test is considered at an end (taken as $0.3 \mathrm{kN}$ ).

The flexibility index (FI) was also determined to quantify the cracking resistance of AC mixtures. The FI depicts the basic fracture mechanism and is derived using loaddisplacement curves produced from the I-FIT technique with fracture energy and slope parameters at the post-peak inflection point [43]. Researchers found that FI can effectively capture changes in the materials and volumetric design of AC mixtures [43,90].

The FI is determined by dividing the total fracture energy by the slope at the inflection point of the post-peak load-displacement curve.

$$
F I=\frac{G_{f a}}{|m|} \times A
$$

where $|m|=$ absolute value of the post-peak slope at the inflection point.

$G_{f a}=$ fracture energy and represents the area under the load-displacement curve normalised by fractured area.

Coefficient $A=$ unit conversion factor and scaling coefficient (taken as 0.01 as the default).

The rate of deterioration of various asphalt mixtures before and after failure was studied. Secant modulus is the slope of the failure of the material between the starting point of the test to the peak load, whereas the post-peak slope is the slope taken at the inflection point.

\subsection{FPBB Test}

The four point bending beam testing was adopted in this study according to AASHTO T321-07. The asphalt mixture fatigue life $\left(\mathrm{N}_{\mathrm{f}}\right)$ is usually described as the number of cycles needed to produce a $50 \%$ reduction in the initial stiffness (flexural) modulus (i.e., the stiffness modulus recorded at the 100th cycle) of an asphalt mixture at a particular strain or stress level. Three beams for each mixture at each condition with dimensions of $63.5 \pm 5 \mathrm{~mm}$ in width, $50 \pm 5 \mathrm{~mm}$ in depth, and $390 \pm 5 \mathrm{~mm}$ in length were prepared. The tests were conducted at $25^{\circ} \mathrm{C}$ and a frequency of $10 \mathrm{~Hz}$ in a strain-controlled mode (300 and 400 micro strain) and sinusoidal loading. The $50 \%$ reduction of the initial flexural modulus was used as a failure criterion.

\section{Data Analysis Technique}

The most important aspect while developing the correlation is to choose the most appropriate data analysis technique to represent the actual fatigue properties of individual materials. The ratio of dissipated energy change (RDEC) approach is an energy-based approach. It can remove other types of dissipated energy caused by mechanical work or heat production, making it a useful metric for describing the fatigue phenomenon in asphalt. The RDEC is described as the difference in dissipated energy between two consecutive cycles divided by the first cycle's dissipated energy:

$$
R D E C_{a}=\frac{D E_{a}-D E_{b}}{D E_{a}(b-a)}
$$


$R D E C_{a}=$ the average ratio of changes in dissipated energy between cycles $a$ and $b$.

$D E_{a}$ and $D E_{b}=$ dissipated energy of cycles $a$ and $b$, respectively, which were calculated using Equation (6).

$$
W_{i}=\pi \sigma_{i} \varepsilon_{i} \sin \delta_{i}
$$

where, $W_{i}=$ dissipated energy at cycle $i, \sigma_{i}=$ stress level at cycle $i, \varepsilon_{i}=$ strain level at cycle $i$, and $\delta_{i}=$ phase angle at cycle $i$.

Figure 4 shows the three different phases of a typical RDEC vs. a loading cycle curve from real FPBB test data for the elastomer-modified asphalt mixtures in this study.

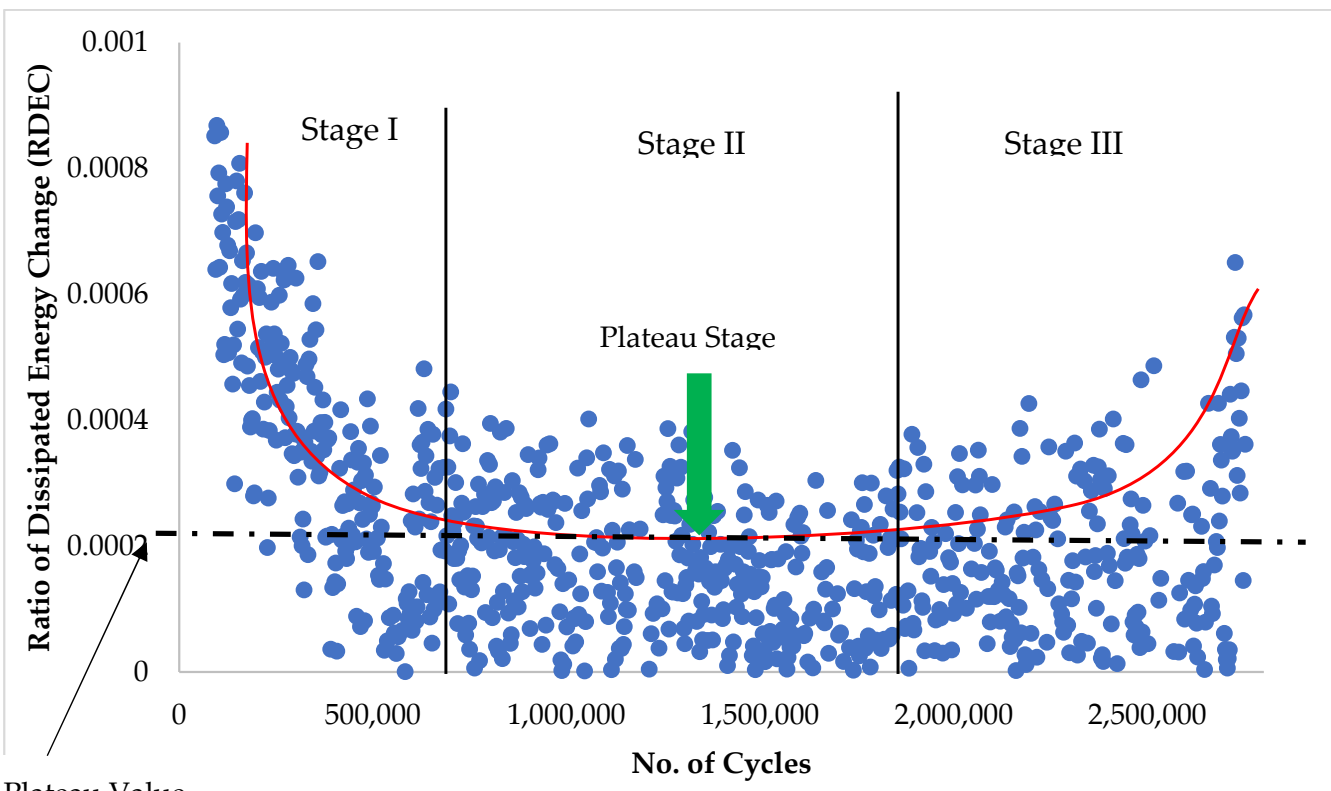

Plateau Value

Figure 4. Plastomers RDEC plot using the approach developed by Carpenter et al. [94].

Figure 5 shows three different phases of a typical RDEC vs. a loading cycle curve to simplify the 'plateau value' approach. Stage II, wherein the RDEC data remains relatively constant, is of particular importance and is referred to as the plateau value (PV). The plateau stage denotes a phase in which a fixed proportion of input energy is transformed into damage.

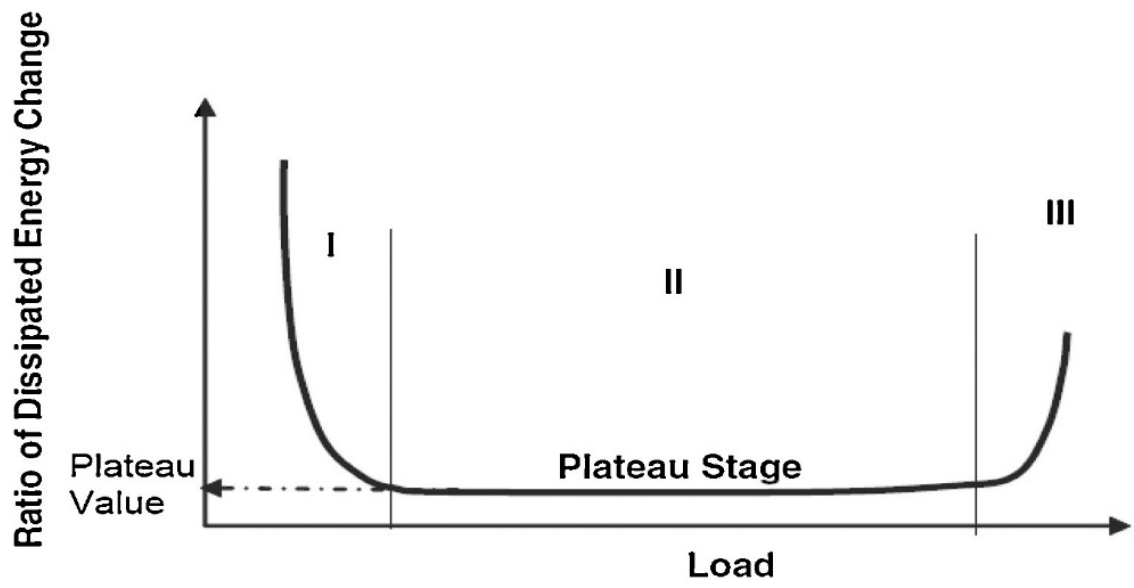

Figure 5. Typical dissipated energy ratio plot with the three characteristic zones [5]. 
The advantage of this method over others, such as the cumulative dissipated energy method, is that it eliminates other types of energy that are dissipated during a cyclic fatigue test, such as thermal energy, and focuses only on the dissipated energy damage. The cumulative dissipated energy (CDE) during the plateau stage, where the RDEC value is constant, was used to explain the fatigue life of asphalt mixes in this study. Furthermore, because of the significant variance in the fatigue data, as illustrated in Figure 4, the Franken model [95] was used to fit the No. of cycles versus dissipated energy data to limit noise in the data (Figure 6).

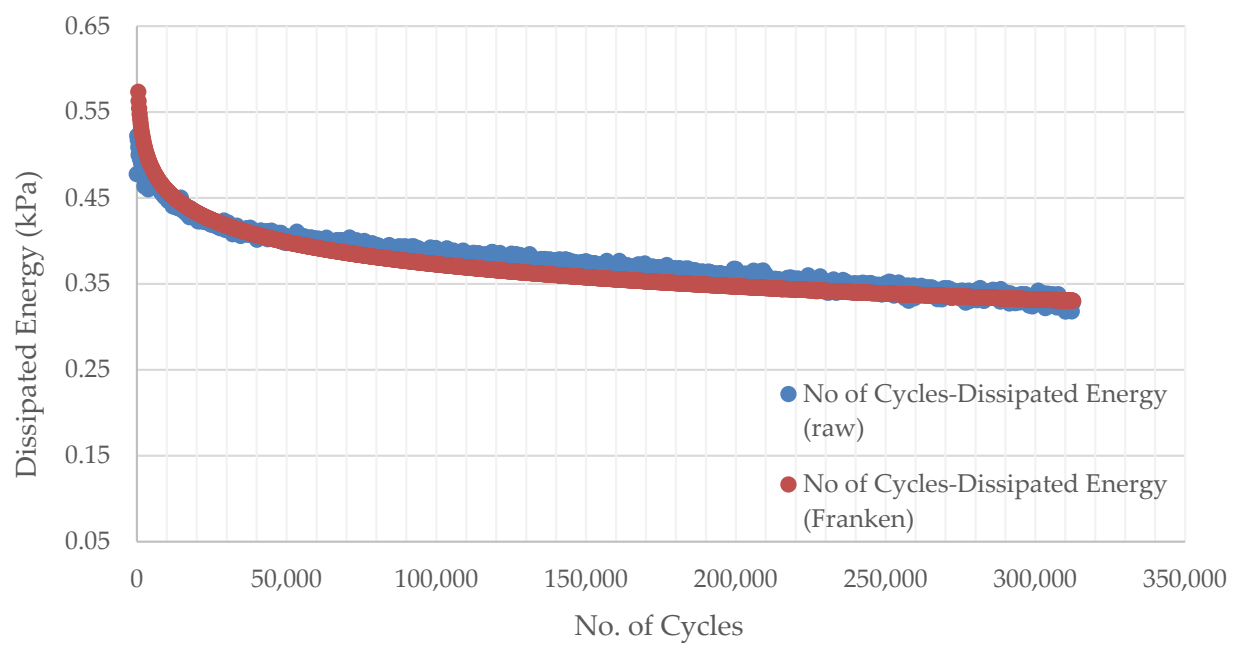

Figure 6. Typical plot between dissipated energy and loading cycles fitted with the Franken model [86].

Carpenter and Shen developed a basic method for performing an RDEC analysis and obtaining the PV from fatigue testing [96]. It entails plotting the dissipated energy (DE) vs. the No. of Cycles $(\mathrm{NoC})$ curve and computing the exponential slope " $\mathrm{k}$ " of the DE-NoC curve of the plateau phase using power-law regression to fit the curve (Figure 7).

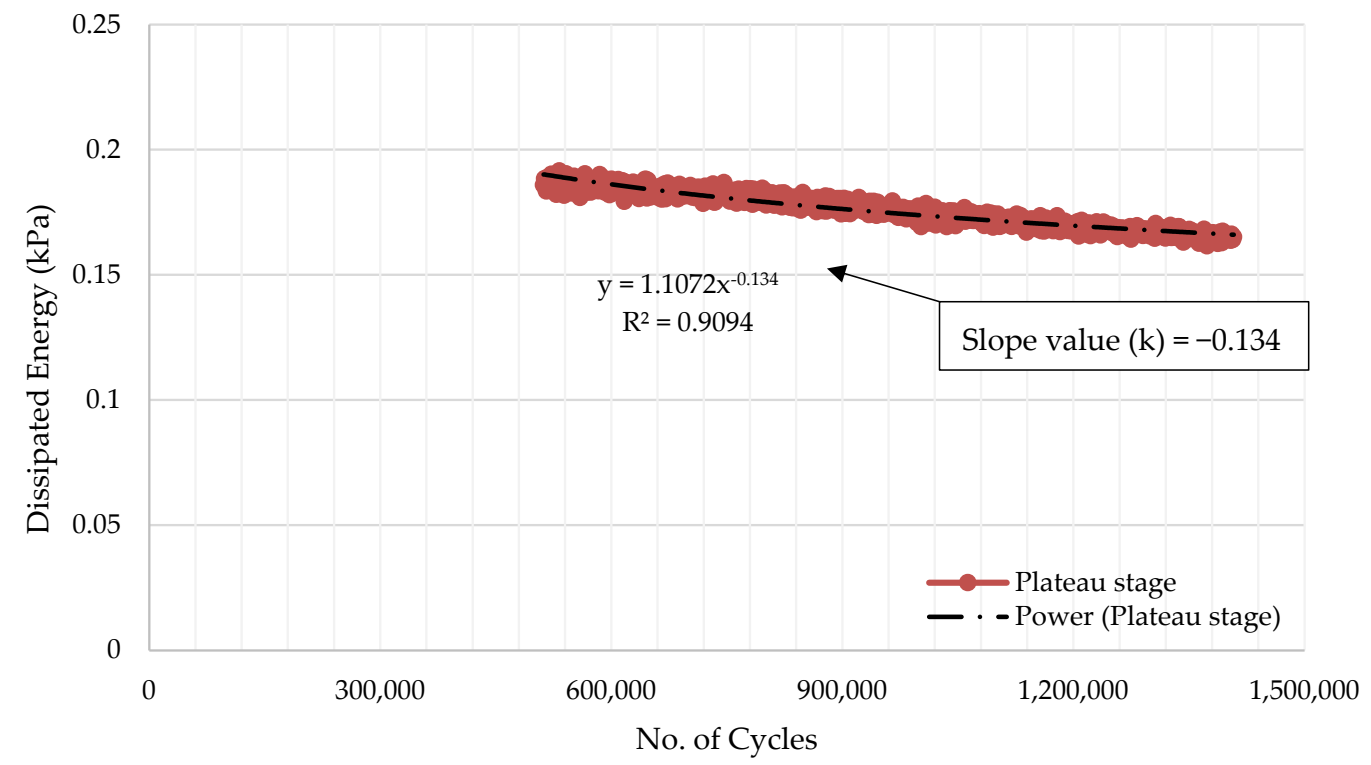

Figure 7. Example of calculation of the exponential slope value (k) of the fitted DE-Loading Cycle for PV computation using Carpenter and Shen's approach [87]. 
Equation (7) is used to compute PV, defined as the RDEC value at the $50 \%$ stiffness reduction failure point $\left(N_{f 50}\right)$.

$$
P V=\frac{1-\left(1+\frac{100}{N f_{50}}\right)^{k}}{100}
$$

$P V$ is a comprehensive damage factor that considers material properties and loading parameters, making it a helpful energy parameter for describing HMA fatigue behaviour [97]. The lower the $P V$ in a strain-controlled test, the greater the fatigue life for a particular HMA mixture [97].

\subsection{Method of Statistical Analysis \\ Linear Regression Analysis}

A linear regression analysis was conducted with a $95 \%$ confidence level to model the correlation between the bitumen and asphalt mixture fatigue properties. A Shapiro-Wilk normality test and descriptive statistics were used to ensure that the data sets had a uniform distribution before performing a regression analysis. The linearity of the relationships between the different variables was also assessed. An R-Square goodness of fit was also utilised to describe the relationship of the cracking characteristics between binders and the corresponding asphalt mixtures in this research. The backwards elimination technique for choosing dependent variables was used to find the optimum correlating variables and conditions for different combinations of materials [98]. Multiple linear regression analyses were performed by selecting all dependent variables one at a time and then variables with a high $p$-value (i.e., a high $p$-value means a higher probability of the null hypothesis being true if indeed the hypothesis is true) and small $\mathrm{t}$-value (i.e., a small $\mathrm{t}$-value shows the reduced significance of a specific variable). A series of regressions were conducted to remove all dependent variables, except for the one with the lowest $p$-value and highest $\mathrm{t}$-value, which was lastly selected for the final statistical model.

Three replicates for each condition were carried out for binders and asphalt mixtures individually, resulting in a total of six observations for each condition for each type of material. The number of data points in each blend group is given in the statistical analysis of each test segment below. For example, there were six materials in all combinations of materials (All Sources), so the number of observations for each condition was eighteen.

\section{Results and Discussion}

\subsection{IDT Test}

\subsubsection{Statistical Analysis}

By grouping all the combinations of unmodified and modified binders-indicated as "All Sources" in Table 7 and grouping all polymer-modified mixes indicated as "PMB Family" in Table 7—the data show correlation values of 0.78 (LAS: N $\mathrm{f}_{\mathrm{f}} @ 5 \%$, IDT: Strength) and 0.93 (LAS: $\mathrm{N}_{\mathrm{f}} @ 2.5 \%$, IDT: Strength), respectively.

Table 7. Pearson coefficients of determinations between binders LAS and asphalt mixtures IDT@ $25^{\circ} \mathrm{C}$. (Green Background = Moderate to High Correlation (Darker Green = Higher Correlation Compared to Lighter Green); Yellow Backgound = Average Correlation;).

\begin{tabular}{|c|c|c|c|c|c|}
\hline \multirow{2}{*}{\multicolumn{2}{|c|}{ Correlated Data }} & \multirow{5}{*}{$\begin{array}{c}\text { Bitumen Test } \\
\text { Parameters }\end{array}$} & \multirow{5}{*}{ Relationship Type } & \multicolumn{2}{|c|}{ Asphalt IDT Test Parameters } \\
\hline & & & & All Sources ${ }^{1}$ & PMB Family $^{2}$ \\
\hline \multirow{3}{*}{ Bitumen Test } & \multirow{3}{*}{$\begin{array}{c}\text { Asphalt Mixture } \\
\text { Test }\end{array}$} & & & \multicolumn{2}{|c|}{ Sample Size for Statistical Analysis } \\
\hline & & & & 36 & 30 \\
\hline & & & & \multicolumn{2}{|c|}{$\mathbf{R}^{2}$ Value } \\
\hline \multirow{2}{*}{ LAS } & \multirow{2}{*}{ IDT } & $\mathrm{N}_{\mathrm{f}} @ 2.5 \%$ Strain & \multirow{2}{*}{ linear $y=a x+b$} & 0.67 & 0.88 \\
\hline & & $\mathrm{N}_{\mathrm{f}} @ 5 \%$ Strain & & 0.78 & 0.93 \\
\hline
\end{tabular}

All sources ${ }^{1}$-The group includes plastomers, elastomers, unmodified bitumen, polymeric compounds with microfibres and amino-wax based mixes, PMB Family ${ }^{2}$ - The group includes plastomers, elastomers, amino-wax based and polymeric compounds with microfibres. 
This research has confirmed that differences in fracture strength exist for different polymer-modified binders at an intermediate temperature and that fracture strength can be one of the predictors that reasonably correlates with the binders' fatigue properties.

Strength properties are highly dependent on the type of binder (i.e., an excessively stiff binder is more prone to contribute to cracking and will fail earlier and vice versa). Therefore, different materials exhibited different strengths based on the material properties at an intermediate temperature and resulted in distinct strength properties. $\mathrm{N}_{\mathrm{f}}$ by a LAS captured each binder's distinct fatigue life, which was also linked with the type of polymer modification and grade of bitumen; therefore, the strongest linear correlation exists at an intermediate temperature for the PMB group of materials. The strong correlation suggests that $\mathrm{N}_{\mathrm{f}}$, which is based on the rheological properties of binders, can help predict the intermediate temperature cracking properties of asphalt mixtures in terms of the indirect tensile strength test.

The outcomes of the LAS test for lower strain level (2.5\%) show less correlation with IDT test results. This can be ascribed to the magnitude of the stresses at $2.5 \%$ strain that could not fully activate the complex polymeric structure (simple structural chain folding, strong intermolecular forces, and containing stiffening groups) [99]. As a result, the lower strain levels in the LAS test could not produce a similar damage pattern as in the IDT test, where the loading rate was very high. For the IDT strength, the asphalt mixtures tested were subjected to a high loading rate, which triggered the response from the polymers' complex structure and better captured the effects of the presence of polymers in the mixes [100] (Figure 8). However, as the level of strain increased in the LAS test, an improved correlation was observed, probably linked to an accelerated reduction in the fatigue life, as higher strain levels activate the complex structures of the polymers, bringing significant changes in the bituminous matrix. This aspect produced outcomes from the binders' testing that were more aligned with IDT test results on asphalt mixtures, hence resulting in a good correlation (Figure 8).

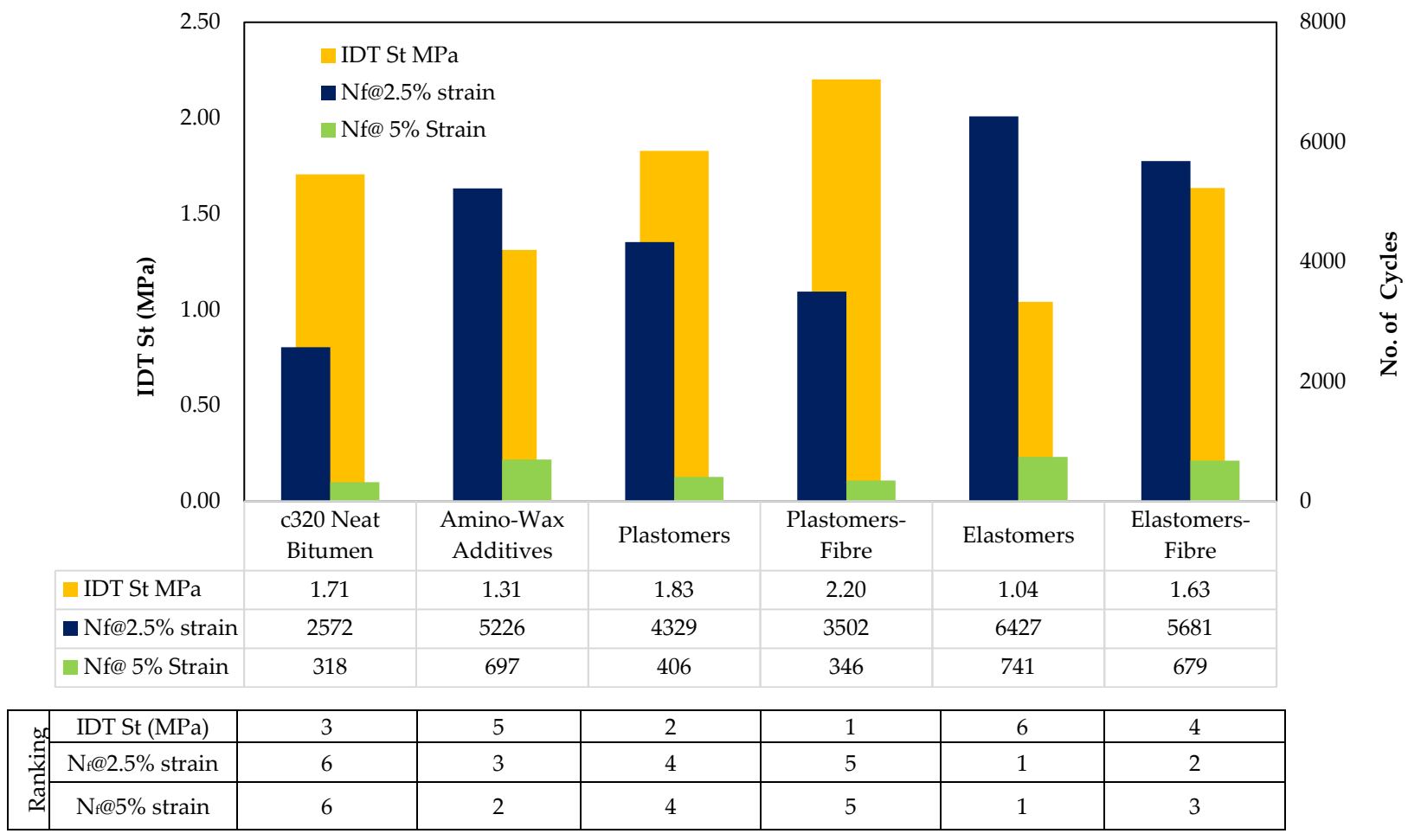

Figure 8. Ranks and Properties of HMA mixes@25 ${ }^{\circ} \mathrm{C}$ for IDT and LAS tests. 


\subsubsection{Model Development}

A regression analysis was carried out for the most efficient pair of parameters at their best testing conditions to construct the model for predicting the asphalt mixture's intermediate temperature cracking properties from the binder's properties. Table 8 presents the results of the regression analysis of different groups of materials.

Table 8. Best correlated parameters and testing conditions between a LAS test@2 $2{ }^{\circ} \mathrm{C}$ on bitumen and IDT@25 ${ }^{\circ} \mathrm{C}$ on asphalt mixtures.

\begin{tabular}{|c|c|c|c|c|c|c|c|c|}
\hline Mix ID & $\begin{array}{c}\text { Bitumen } \\
\text { Testing } \\
\text { Parameter }\end{array}$ & $\begin{array}{c}\text { Asphalt } \\
\text { Testing } \\
\text { Parameter }\end{array}$ & $\mathbf{R}^{2}$ & $\begin{array}{c}\text { Adjusted } \\
\mathbf{R}^{2}\end{array}$ & t Stat & $p$-Value & $\begin{array}{c}\mathrm{X} 1 \\
\text { Variable }\end{array}$ & Intercept \\
\hline All Sources & $\mathrm{N}_{\mathrm{f}} @ 5 \%$ & IDT & 0.785 & 0.742 & -4.271 & 0.008 & -0.002 & 2.658 \\
\hline $\begin{array}{l}\text { PMB } \\
\text { Family }\end{array}$ & $\mathrm{N}_{\mathrm{f}} @ 2.5 \%$ & IDT & 0.927 & 0.902 & -6.152 & 0.009 & 0.000249 & 3.180 \\
\hline
\end{tabular}

For instance, to simplify the information given in Table 8, the regression analysis outputs should read as analytical equations as per the examples provided below.

$$
\begin{array}{ll}
I D T(\mathrm{MPa})=-0.002\left(N_{f} @ 5 \%\right)+2.658 & \text { All Sources } \\
\operatorname{IDT}(\mathrm{MPa})=2.49 \times 10^{4}\left(N_{f} @ 2.5 \%\right)+3.180 & \text { PMB Family }
\end{array}
$$

\subsubsection{Ranking of Binders and Asphalt Mixtures}

The binders and mixtures were ranked and were assigned 1 to 6 ranks in Figure 8, where the lowest number represents the best performing and the higher number indicates least performing in cracking.

\subsection{SCB Test Results}

\subsubsection{Statistical Analysis}

By grouping, all the combinations of unmodified and modified binders-indicated as "All sources" - the data show the highest correlation value of 0.97 (LAS: $\mathrm{N}_{\mathrm{f} @ 5 \%} \%$, SCB: Secant Modulus), whereas by grouping all polymer-modified mixes (PMB family), the highest correlation value of 0.98 (LAS: $\mathrm{N}_{\mathrm{f}} @ 5 \%$, SCB: Strength \& Secant Modulus) was obtained. Following the ANOVA, a least-square regression analysis was performed to explore trends in the data further. Table 9 shows the relationship between bitumen fatigue parameters and asphalt cracking parameters.

In general, there was a poor correlation between fracture energy and fatigue life of bitumen for "All Sources" and "PMB Family." The fracture energy poor correlation can be explained by taking into account the work required before failure of the sample for different materials; for instance, elastomer materials will experience less force at the time of failure than plastomers, which are generally stiffer. On the other hand, the deformation required by elastomers to reach $50 \%$ stiffness will be high compared to plastomers, resulting in similar work, as this is the product between force and deformation for all types of materials. Figure 3 is a very good illustration of the fracture energy of all mixtures. Secant modulus and post peak slope are essential considerations while analysing the asphalt cracking data because they give an idea about the material deterioration rate during SCB testing. The slope resulted in the best performing SCB parameter to correlate with the number of cycles of the LAS of bitumen. A material that develops a high slope will ultimately result in faster cracking propagation. As it has been observed, asphalt mixes modified with elastomers sustain a greater number of cycles to failure, as they possess more elastic behaviour under repetitive loading; a similar trend was observed for the post-peak slope. Each material has shown distinct behaviour even after reaching the maximum load, as the load-carrying capacity was transferred to the bitumen and aggregate interface and cohesive properties 
of bitumen. Materials with more elastic characteristics possess more tensile properties and generate smaller slope values and vice versa. The second-best correlation parameter between LAS and SCB was strength. Plastomers showed higher tensile strength, whereas the elastomer-modified asphalt samples collapsed at lower force values. The strength was negatively correlated with the fatigue life of binders under the constant deformation test (Table 10).

Table 9. Pearson coefficients of determinations between binders' LAS and asphalt mixtures' SCB tests; (Green Background = Moderate to High Correlation (Darker Green = Higher Correlation Compared to Lighter Green); Yellow Backgound = Average Correlation; Red Background = Poor Correlation).

\begin{tabular}{|c|c|c|c|c|c|c|c|c|}
\hline \multicolumn{5}{|c|}{ Correlated Data } & \multicolumn{4}{|c|}{ Bitumen Parameters-LAS test } \\
\hline \multirow{4}{*}{$\begin{array}{l}\text { Bitumen } \\
\text { Test }\end{array}$} & \multirow{4}{*}{$\begin{array}{c}\text { Asphalt } \\
\text { Mixture Test }\end{array}$} & \multirow{4}{*}{ Temperatures } & \multirow{4}{*}{$\begin{array}{l}\text { Relationship } \\
\text { Type }\end{array}$} & \multirow{4}{*}{$\begin{array}{c}\text { Asphalt } \\
\text { SCB Test } \\
\text { Parameters }\end{array}$} & $\begin{array}{c}\mathrm{N}_{\mathrm{f} @ 2.5 \%} \\
\text { Strain }\end{array}$ & $\begin{array}{l}\mathbf{N}_{\mathrm{f}} @ 5 \% \\
\text { Strain }\end{array}$ & $\begin{array}{l}\mathrm{N}_{\mathrm{f}} @ 2.5 \% \\
\text { Strain }\end{array}$ & $\begin{array}{l}\mathrm{N}_{\mathrm{f}} @ 5 \% \\
\text { Strain }\end{array}$ \\
\hline & & & & & \multicolumn{2}{|c|}{$\begin{array}{c}\text { Sample Size for Statistical } \\
\text { Analysis }=36\end{array}$} & \multicolumn{2}{|c|}{$\begin{array}{c}\text { Sample size for Statistical } \\
\text { Analysis }=30\end{array}$} \\
\hline & & & & & \multicolumn{2}{|c|}{ All Material Sources } & \multicolumn{2}{|c|}{ PMB Family } \\
\hline & & & & & \multicolumn{4}{|c|}{$R^{2}$ Value } \\
\hline \multirow{5}{*}{ LAS } & \multirow{5}{*}{ SCB test } & \multirow{5}{*}{$25^{\circ} \mathrm{C}$} & \multirow{5}{*}{$\begin{array}{c}\text { linear } y=a x \\
+b\end{array}$} & $\begin{array}{l}\text { Fracture Energy } \\
\left(\mathrm{kJ} / \mathrm{m}^{2}\right)\end{array}$ & 0.24 & 0.4 & 0.25 & 0.28 \\
\hline & & & & Strength (MPa) & 0.8 & 0.85 & 0.92 & 0.97 \\
\hline & & & & Slope & 0.64 & 0.8 & 0.95 & 0.98 \\
\hline & & & & Flexibility Index & 0.71 & 0.67 & 0.75 & 0.77 \\
\hline & & & & $\begin{array}{l}\text { Secant Modulus } \\
(\mathrm{kN} / \mathrm{mm}) \text { : }\end{array}$ & 0.94 & 0.97 & 0.98 & 0.98 \\
\hline
\end{tabular}

Table 10. Best correlated parameters and testing conditions of bitumen LAS parameter with SCB@ $\left.25^{\circ} \mathrm{C}\right)$.

\begin{tabular}{cccccccc}
\hline Mix ID & $\begin{array}{c}\text { Bitumen Testing } \\
\text { Parameter }\end{array}$ & $\begin{array}{c}\text { Asphalt Mixture } \\
\text { Testing Parameter }\end{array}$ & $\mathbf{R}^{2}$ & $\begin{array}{c}\text { Adjusted } \\
\mathbf{R}^{2}\end{array}$ & $\begin{array}{c}\mathbf{X} \text { Intercept } \\
\text { Variable }\end{array}$ \\
\hline All Sources & $\mathrm{N}_{\mathrm{f}} @ 5 \%$ & Secant Modulus & 0.970 & 0.963 & -12.609 & 0.000 \\
PMB family & $\mathrm{N}_{\mathrm{f}} @ 5 \%$ & Strength & 0.974 & 0.974 & -10.620 & 0.002 & -0.013 \\
\hline
\end{tabular}

The flexibility index was also found to be a valuable parameter to predict the fatigue life of bitumen. As FI relies on fracture energy and post-peak slope, materials with high fracture energy and lesser post-peak slope are considered a good performing material. Since the fracture energy value was less variable between various asphalt mixes, the postpeak slope mainly affected the FI value. Asphalt mixes with higher FI performed well in the LAS and resulted in a greater number of cycles and vice versa. Hence, those trends resulted in a good correlation.

The effect of the test strain level was found similar to what was already discussed in the previous section for the IDT test. A slightly improved correlation is attributed to high strain levels, which mobilise the polymeric chain and lead to permanent changes in the bituminous matrix that are more similar to what is experienced by the asphalt during SCB tests.

\subsubsection{Model Development}

A regression analysis was carried out for the most efficient pair of parameters at their best testing conditions to construct the model for predicting the asphalt mixture's intermediate temperature cracking properties from the binder's properties. Table 10 presents the results of the regression analysis of different groups of materials.

For instance, to simplify the information given in Table 10, the regression analysis outputs should read as analytical equations as per the examples provided below.

$$
\text { Secant Modulus }\left(\frac{\mathrm{kN}}{\mathrm{mm}}\right)=0.013\left(N_{f} @ 5 \%\right)+11.223 \quad \text { All Sources. }
$$




$$
\text { Strength }(\mathrm{MPa})=0.001\left(N_{f} @ 5 \%\right)+0.858 \quad \text { PMB Family }
$$

\subsubsection{Ranking of Binders and Asphalt Mixtures}

The mixtures were ranked and were assigned 1 to 6 ranks in Figure 9, where the lowest number represents the best performing and the higher number indicates least performing in cracking. Binder ranks based on LAS have already been referred to in Figure 8.

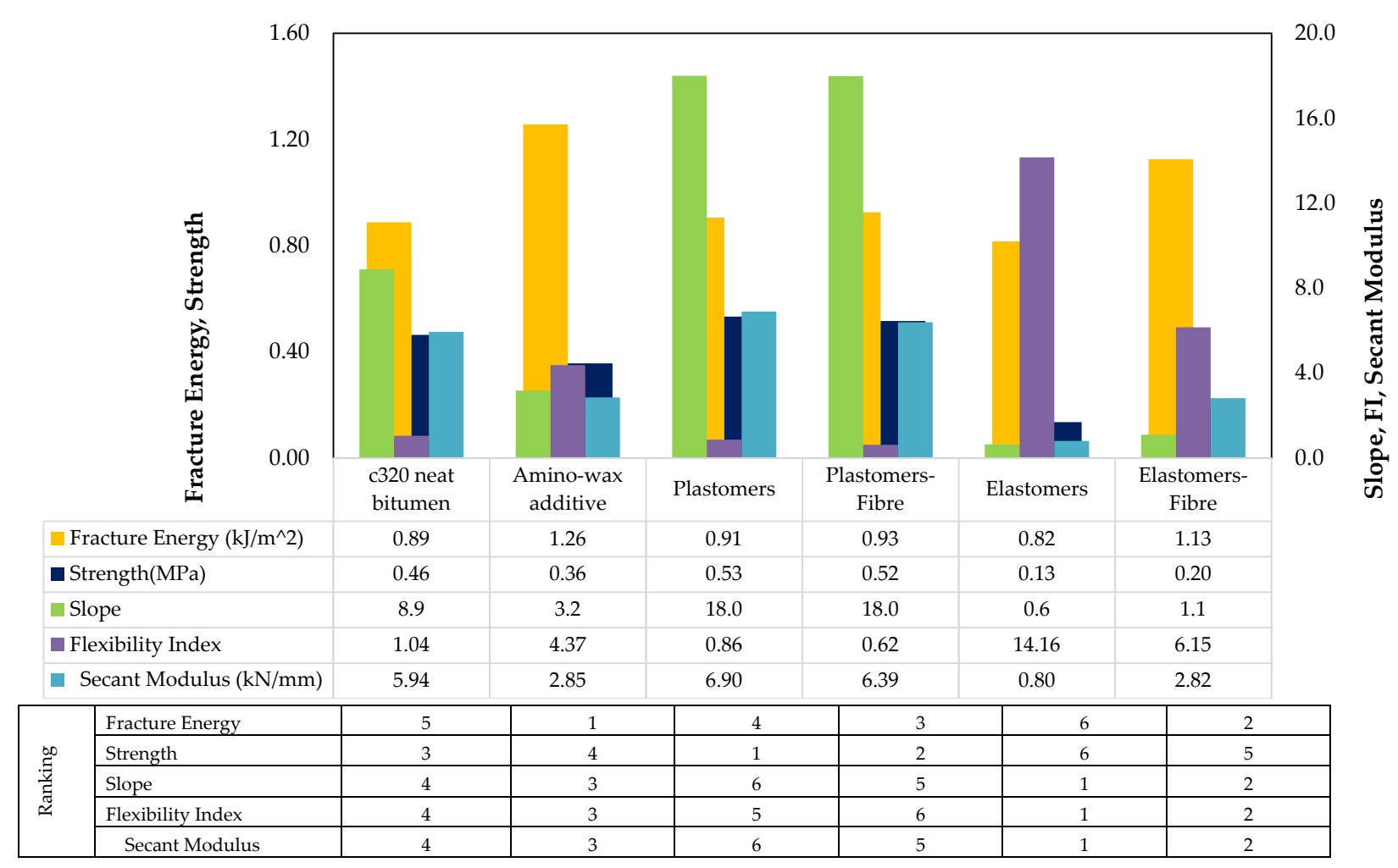

Figure 9. Ranking and properties of HMA mixes@25 ${ }^{\circ} \mathrm{C}$ for the SCB test.

\subsection{Four Point Bending Beam Test}

\subsubsection{Statistical Analysis}

A statistical analysis (ANOVA) was conducted to identify the bitumen parameters that significantly affected the fatigue cracking potential of asphalt mixtures. A value of

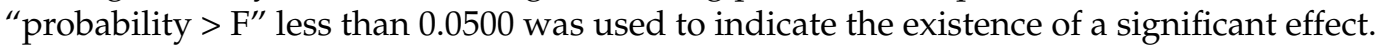
$\mathrm{N}_{\mathrm{f}} @ 2.5 \%$ and $\mathrm{N}_{\mathrm{f}} @ 5 \%$ were found to affect fatigue cracking parameters of asphalt mixtures significantly. $\mathrm{N}_{\mathrm{f}} @ 2.5 \%$ of LAS of "all sources" had a greater significant effect on the fatigue cracking potential with a "probability $>F^{\prime}$ " value being less than 0.01 . Table 11 shows the relationship between bitumen fatigue parameters and asphalt fatigue parameters.

An improved correlation between LAS testing parameters and FPBBT fatigue indicators was observed compared to LAS parameters and fracture energy in SCB tests. This is probably linked to the different types of dissipated energy linked to the type of testing. In LAS and FPBB tests, the repetition of several loading cycles converts part of the dissipated mechanical energy into heat (thermal energy) due to the viscoelasticity of the material that provides a damping effect and reduces the damage due to fatigue. Cyclic tests on asphalt samples also incorporate a minimal portion of healing due to the self-recovery ability of the asphalt binders that is not considered by other failure tests, such as the SCB, which are mostly focused on strain-energy release and fracture properties. In general, PV showed a better correlation with the LAS ' $\mathrm{N}_{\mathrm{f}}$ ' parameters than CDE. PV, calculated through the RDEC concept, only considers the portion of the energy that produces crack extension, e.g., without considering the thermal energy or plastic deformation. Similarly, the VECD 
approach uses continuum damage mechanics based on the work potential to quantify microcracking. Although VECD does not consider the change of time dependency in terms of phase angle, the model is considered to be more similar to the dissipated energy in FPBBT.

Table 11. Pearson coefficients of determinations between asphalt binders and mixtures for FPBBT; (Green Background = Moderate to High Correlation (Darker Green = Higher Correlation Compared to Lighter Green); Yellow Backgound = Average Correlation; Red Background = Poor Correlation).

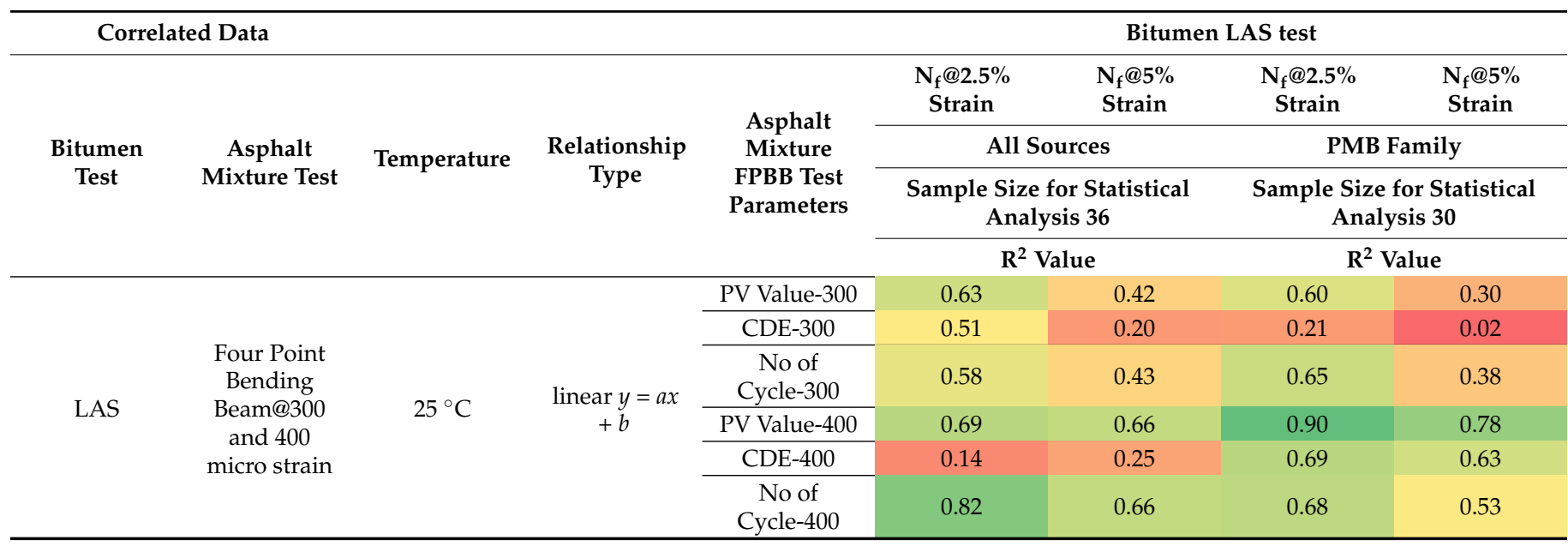

\subsubsection{LAS vs. PV}

By grouping all the combinations of unmodified and modified binders-indicated as "All Sources" - the data show the highest correlation value of 0.69 (LAS: $\mathrm{N}_{\mathrm{f}} @ 2.5 \%$, FPBBT: PV Value-300) and by grouping all polymer-modified mixes ("PMB family"), the highest correlation value of 0.90 (LAS: $\mathrm{N}_{\mathrm{f}} @ 2.5 \%$, FPBBT: PV Value-400) was obtained. PV value was found to exhibit a good correlation for "PMB Family" at 400 micro strains compared to 300 micro strains. This can be explained by the intensity of two different strain levels; as the strain levels increase, materials with similar fatigue characteristics start showing more prominent difference of behaviour, as high strains activate the complex structures of polymer-modified binders and produce permanent changes in the microstructure of binders, and the tendency to recover the fatigue damage decreases. At a lower rate of deformation, fatigue curves are missing clear differentiation of the various phases of fatigue damage. At higher strains, materials are subjected to higher force amplitude and exhibit three separate phases of degradation; therefore, the PV value can be captured with more accuracy at high strain, which is why they correlated well at $400 \mu$ strain. Overall, the correlation has been found moderate for "All Sources", and this could be explained as the binders in various asphalt groups possessed similar properties, resulting in PV values with less variance. However, it should be noted that the PV value is affected by both the slope and the number of cycles. Different materials could possess a similar slope of failure but require different cycles to reach the 50\% stiffness reduction. As a result, the PV value can lead to complex behaviours for a similar group of binders with smaller variations involved.

\subsubsection{LAS vs. CDE}

By grouping all the combinations of unmodified and modified binders-indicated as "All Sources" - the data show the highest correlation value of 0.51 (LAS: $\mathrm{N}_{\mathrm{f}} @ 2.5 \%$, FPBBT: CDE-300), and by grouping all polymer-modified mixes (PMB family), the highest correlation value of 0.69 (LAS: $\mathrm{N}_{\mathrm{f}} @ 2.5 \% @$, FPBBT: CDE-400) was obtained. In general, there was a poor correlation between CDE-400 and the fatigue life of bitumen for "All Sources" of binders because the CDE value of neat bitumen was quite indifferent due to having a high vulnerability of cracking than the polymer-modified binders. This can 
be explained by considering the very high dissipated energy produced at $400 \mu$ strain for unmodified bitumen, which indicates the tendency to rebound is very low, and unmodified bitumen is vulnerable to slightly increased traffic loading. In order to resist fatigue cracking, an asphalt binder should be elastic in nature and should dissipate less energy. A high correlation value was obtained for PMB at 400 micro strain because many softer mixes (elastomers and amino-wax-based additives) produced less dissipate energy at $300 \mu$ strain on the beams; however, more cycles resulted from good recovery properties reaching the $50 \%$ stiffness reduction.

On the other hand, stiff mixes experienced the tertiary stage of degradation, which indicates they were degrading faster in terms of fatigue properties, so fewer cycles were reported to reach a $50 \%$ stiffness reduction. Therefore, resistance against fatigue of different materials at $400 \mu$ strain is quite different, and so the CDE at $400 \mu$ strain was found indifferent, and, ultimately, a comparatively better correlation than $400 \mu$ strain was found. The trend was indifferent at 300 micro strain, where a high correlation value was obtained for all sources and less for PMB sources. This indicates that a lesser strain can help to predict the overall asphalt mixture's fatigue behaviour using LAS data at $2.5 \%$; however, the complex structure of polymer compounds in the PMB family does not activate at a lesser strain and does not truly characterise the asphalt mixtures.

\subsubsection{LAS vs. NoC}

By grouping all the combinations of unmodified and modified binders togetherindicated as "All Sources" - the data show the highest correlation value of 0.82 (LAS: $\mathrm{N}_{\mathrm{f}} @ 2.5 \%$, FPBBT: No of Cycle-400), and by grouping all polymer-modified mixes (PMB family), the highest correlation value of 0.68 (LAS: $\mathrm{N}_{\mathrm{f}} @ 2.5 \%$, FPBBT: No of Cycle-400) was obtained. The fatigue life of binders and asphalt mixtures was thus correlated with the number of cycles to address the above issue. The correlation was significant. This study counted only those loading cycles to determine the fatigue life of asphalt mixtures involved in the secondary zone (plateau stage). Using the Franken model, the data were fitted. The tangent was drawn at the primary zone (mechanical loss), and another tangent was drawn for the secondary zone. The number of cycles was calculated by deducting the primary zone cycles from the total number at the end of the secondary zone. This technique captured the true fatigue properties of each asphalt mixtures' type and resulted in a different fatigue life similar to binders determined in the LAS test. Therefore, the number of cycles of the FPBB test in the secondary zone positively correlated with the fatigue life of the LAS test of various binders. Overall, the same trend was observed; as in the case of the PV value and CDE parameter, the high correlation of LAS at $2.5 \%$ was observed at 400 micro strain, except "All Sources "showed the poor correlation of CDE at 400 micro strain.

The behaviour of various materials under the FPBB test (repeated loading at a given frequency) is different from the IDT and SCB tests (constant loading rate test) due to differences in the dynamics of the testing methods. The FPBB test is more similar to LAS in the sense that it involves repeated loading cycles at a certain frequency. The correlation of NoC from the FPBB test at 300 and 400 micro strain was moderate to high with the LAS No. of cycles to failure, particularly at $2.5 \%$ strain. Furthermore, as it can be inferred from the NoC results (Figures 10 and 11) of the various asphalt mixtures at 300 and 400 micro strain, the imposed level of strain produced a number of cycles to failure in the order of $10^{5}-10^{6}$, hence suggesting greater strain levels would have been needed to correlate better with LAS tests at $5 \%$ strain. The rise from $2.5 \%$ to $5 \%$ represents a double increase in the strain level for the LAS test on bitumen, whereas shifting from 300 to 400 micro strain for the strain-controlled FPBB test on the asphalt mixture corresponds to a $33 \%$ increase. Testing at higher strain levels, particularly for polymer-modified mixtures, is therefore recommended to possibly observe a greater correlation with LAS tests at $5 \%$ strain. 


\subsubsection{Model Development}

Regression analyses were carried out for the most efficient pair of fatigue parameters from LAS and FPBB tests at their best testing conditions to construct the model for predicting asphalt mixtures fatigue cracking properties from the binder's properties. Table 12 presents the results of the regression analysis of different groups of materials.

Table 12. Best correlated parameters and testing conditions of bitumen LAS@25 ${ }^{\circ} \mathrm{C}$ with asphalt mixture; Four Point Bending Beam tests at $300 \mu$ strain and $400 \mu$ strain@ $25^{\circ} \mathrm{C}$.

\begin{tabular}{|c|c|c|c|c|c|c|c|c|c|}
\hline Mix ID & $\begin{array}{l}\text { Bitumen } \\
\text { Testing } \\
\text { Condition }\end{array}$ & $\begin{array}{c}\text { Asphalt Mixture } \\
\text { Testing } \\
\text { Parameter }\end{array}$ & $\begin{array}{c}\text { Asphalt Mixture } \\
\text { Testing } \\
\text { Condition }\end{array}$ & $\mathbf{R}^{2}$ & $\begin{array}{c}\text { Adjusted } \\
\mathbf{R}^{2}\end{array}$ & t Stat & $\begin{array}{c}p- \\
\text { Value }\end{array}$ & $X_{1}$ Variable & Intercept \\
\hline All Sources & $\begin{array}{c}\mathrm{N}_{\mathrm{f}} @ 2.5 \% \\
\text { strain }\end{array}$ & No of Cycles@400 & $25^{\circ} \mathrm{C}$ & 0.82 & 0.78 & 4.28 & 0.01 & 46.17 & $-26,930$ \\
\hline $\begin{array}{c}\text { PMB } \\
\text { Family }\end{array}$ & $\begin{array}{l}\mathrm{N}_{\mathrm{f}} @ 2.5 \% \\
\text { strain }\end{array}$ & PV Value-400 & $25^{\circ} \mathrm{C}$ & 0.90 & 0.87 & -5.2 & 0.01 & $-2.61 \times 10^{-4}$ & 1.89 \\
\hline
\end{tabular}

For instance, to simplify Table 12, the regression analysis outputs should read as analytical equations as per the examples provided below.

$$
\begin{gathered}
\text { No of Cycles@400 } \mu \text { strain }=46.17\left(N_{f} @ 2.5 \% \text { strain }\right)-26,930 \quad \text { All Sources } \\
\text { No of Cycles@400 } \mu \text { strain }=-2.61 \times 10^{-4}\left(N_{f} @ 2.5 \% \text { strain }\right)+1.89 \text { PMB Family }
\end{gathered}
$$

\subsubsection{Ranking of Binders and Asphalt Mixtures}

The mixtures were ranked and were assigned 1 to 6 ranks in Figures 10 and 11, where the lowest number represents the best performing and the higher number indicates least performing in cracking. Binder ranks based on LAS have already been referred to in Figure 8.

\subsection{Fatigue Behaviors of Various Materials}

For the given binders and asphalt mixtures, fatigue properties can be explained as follows:

$\mathrm{PV}$ value is an important consideration while analysing the fatigue data because it helps to give an idea about the material deterioration rate during the fatigue cracking phenomenon. PV value relies on the slope of the secondary zone and the total number of cycles required to reach a 50\% stiffness reduction. Having a high PV value is an indication of rapid deterioration of the material and vice versa. Materials with a high potential of propagating the cracking were found to have a high PV value because of the high rate of deterioration during fatigue testing, resulting in fewer cycles to reach a $50 \%$ stiffness reduction.

\subsection{1. $\mathrm{N}_{\mathrm{f}}$ and PV Value}

Mixed Modified with Elastomers: For mixtures with elastomers and elastomer/fibre, the fatigue life increased by $1234 \%$ and $417 \%$ at $300 \mu$ strain and $216 \%$ and $212 \%$ at $400 \mu$ strain, respectively. Hence, the effect of elastomer modification was found beneficial in FPBB tests. Similarly, the PV value for elastomer- modified materials was reduced, which supports a lower deterioration rate (longer fatigue life) under repetitive loading, making elastomers more favourable to resist fatigue. 


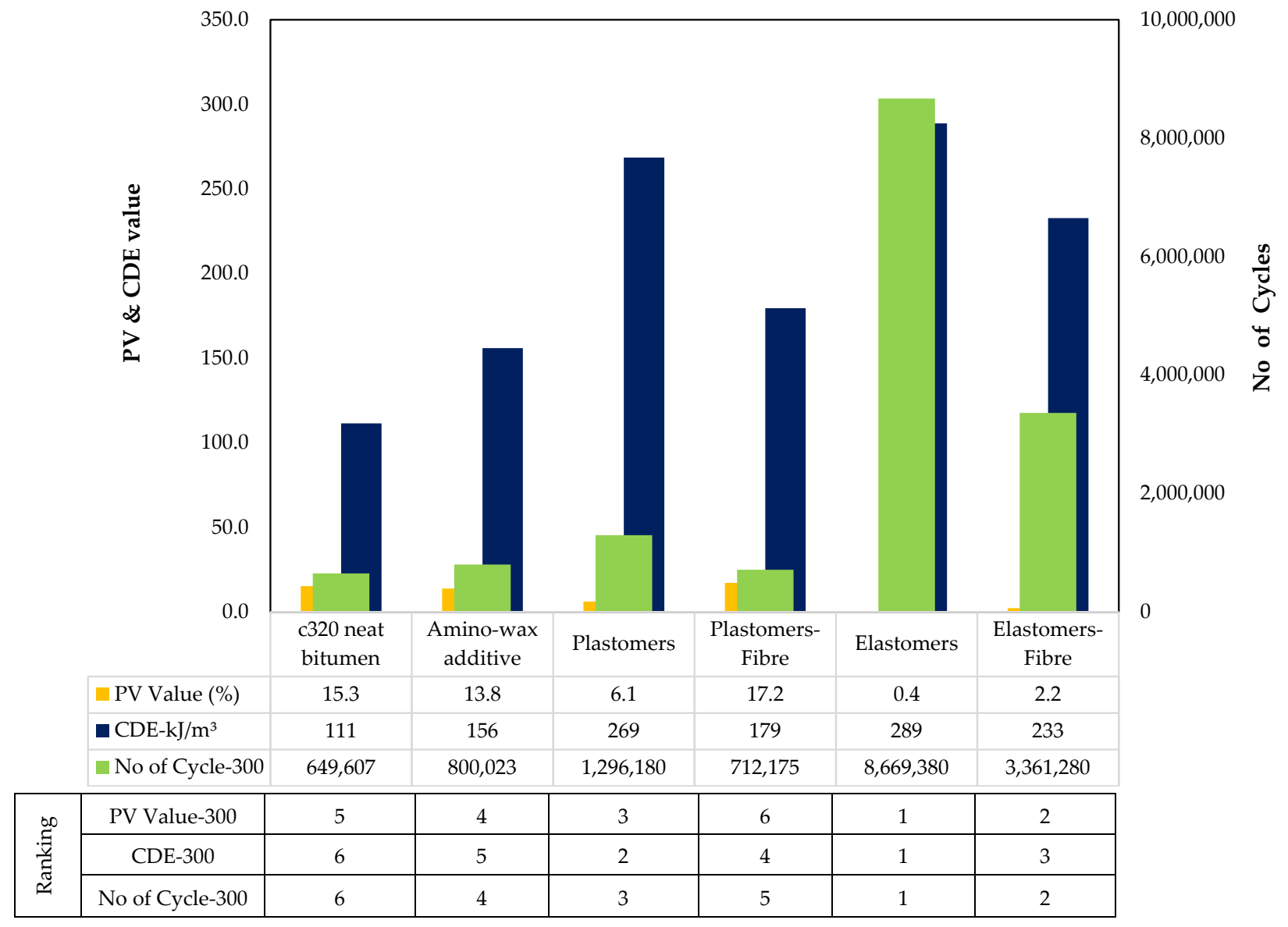

Figure 10. Ranking and properties of HMA mixes@300 $\mu$ strain for FBBT tests.

Mixed Modified with Plastomers: For mixtures with the plastomers and plastomers / fibre, the fatigue life increased by $99 \%$ and $10 \%$ at $300 \mu$ strain and $72 \%$ and $100 \%$ at $400 \mu$ strain. Similar trends were found for the PV value of plastomer-modified materials. The PV value for plastomer-modified materials increased, which suggests a greater deterioration rate (lesser fatigue life) under repetitive loading, making plastomers less favourable to cope with fatigue than elastomers. However, the literature already mentioned how fewer cycles to fatigue are reported under constant strain mode for plastomer-modified asphalt. Therefore, the cumulative dissipated energy approach was investigated to further study the fatigue performance of this material.

\subsubsection{CDE Value}

In order to resist fatigue cracking, an asphalt binder should be elastic (able to dissipate energy by rebounding and not cracking) but not too stiff (excessively stiff materials crack rather than deform then rebound). Therefore, the dissipated energy per cycle should be minimal to resist fatigue.

Mixed Modified with Elastomers: For mixtures incorporating elastomers and elastomer/fibre, the CDE value decreased by $-80 \%$ and $-59 \%$ at $300 \mu$ strain and $-78 \%$ and $-56 \%$ at $400 \mu$ strain, respectively. Hence, the effect of elastomer modification positively affected FPBB fatigue properties.

Mixed Modified with Plastomers: For mixtures with plastomers and plastomers/fibre, the CDE value was $21 \%$ and $47 \%$ at $300 \mu$ strain and $-20 \%,-17 \%$ at $400 \mu$ strain, respectively. 


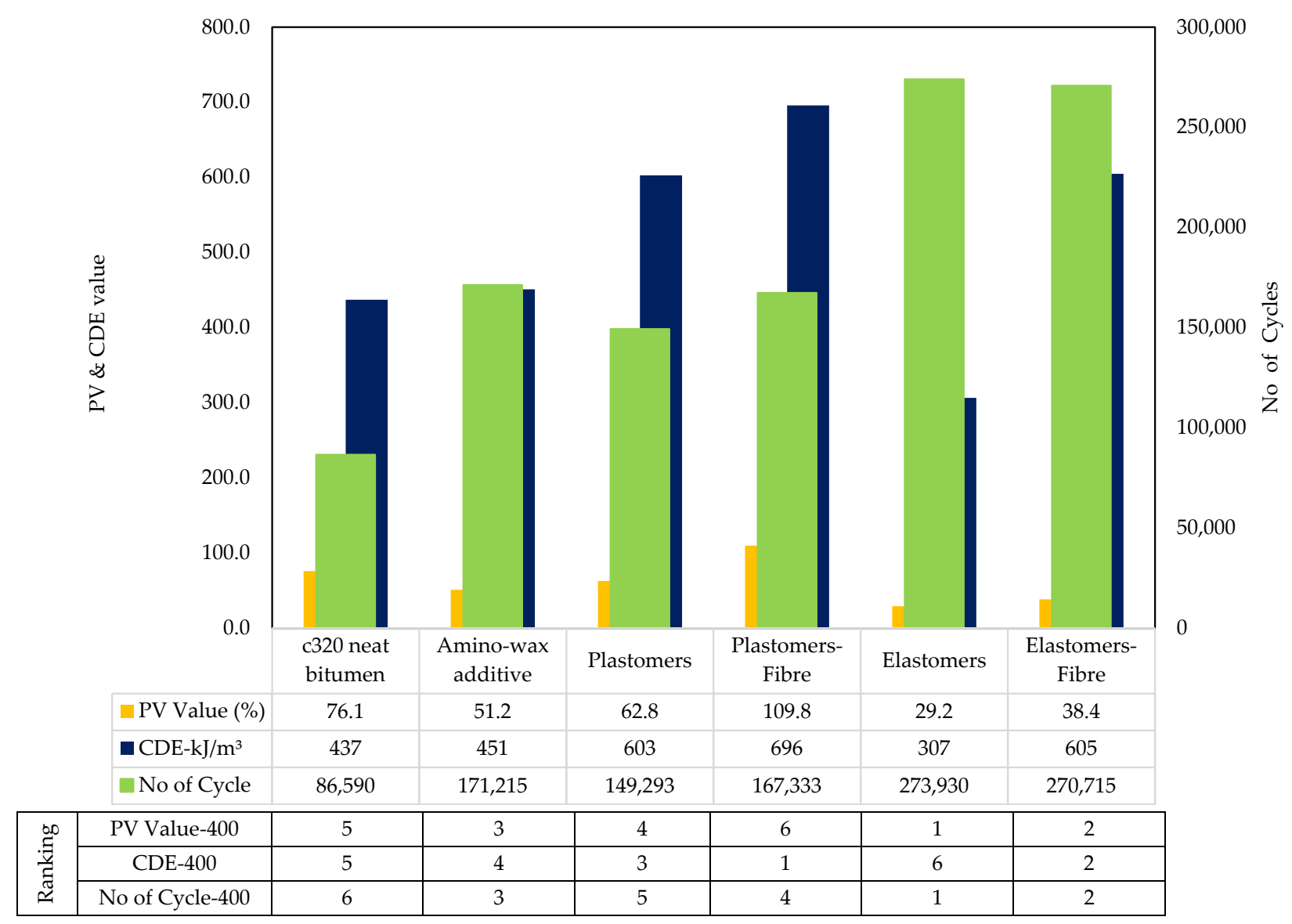

Figure 11. Ranking and properties of HMA mixes@400 $\mu$ strain for FBBT tests.

\subsection{Relationship between Cracking Tests}

The comparison between rankings of monotonic cracking tests (IDT and SCB) and dynamic tests (FPBB test) was made to evaluate the cracking potential of various asphalt mixtures at an intermediate temperature. Rankings given by IDT strength and SCB fracture strength parameters were mostly similar. The slight difference can be linked to the shape of the sample, the effect of the notch, and the rate of loading. Recent studies have suggested that the SCB test involves a fracture-based mechanistic approach that is considered more advanced to determine the cracking potential compared to IDT testing. SCB and FPBB tests were compared to see the effectiveness of cracking characterisation, despite these testing techniques being different.

Various performance indicators calculated based on the SCB test results, i.e., fracture energy (Gf), flexibility index (FI), fracture strength, and slope and secant modulus were compared with the FPBB test results. Based on the FPBBT results, it was shown that the ranking between the six asphalt mixtures considered in this study correspond to those given by the SCB test parameters, except for the indicator 'fracture energy'. These findings are similar to the recent study by Aksel Seitllari et al. [44], where the fatigue test (uniaxial tension-compression) results were compared with SCB test performance indicators. The results of the research confirmed the capability of the SCB test to discriminate the mixes for their cracking potential.

Fracture energy in SCB tests may provide a different ranking, as it is controlled by two different components: maximum load and deformation. Therefore, a probability exists where two asphalt mixtures modified with different families of polymers can produce similar fracture energy. For example, elastomers, plastomers, plastomers-fibres, and neat bitumen showed almost similar fracture energy, despite a different failure load and defor- 
mation at failure. For other SCB parameters, the difference within polymeric families and types of asphalt mixtures is significant, making them a reliable indicator to differentiate between mixes.

Fracture energy is also affected by the sample geometry, especially in the case of heterogeneous material, such as asphalt concrete [101].

\section{Summary of Results}

Several binders (unmodified and modified with different polymers/additives) and their corresponding asphalt mixes were studied in this research. The testing matrix was explicitly designed to assess the binder's fatigue performance at an average pavement temperature through a rheological experiment (linear amplitudes sweep test) of binders and determination of load-induced cracking potential (crack initiation and propagation) of the asphalt mixtures through indirect tensile strength, semi-circular bending, and four point bending beam tests. The goal was to compare and assess the relationship between binders and related asphalt mixture properties using various laboratory techniques and materials. Conventional cracking parameters of IDT and SCB, namely tensile strengths, fracture strength, fracture energy, and newer ones such as PV, CDE, and $\mathrm{N}_{\mathrm{f}}$ of FPBBT, explicitly designed to capture true fatigue behaviour were compared. Secant Modulus through SCB emerged as one of the best potential indicators to enhance the correlation of all tested binders and asphalt mixes. Overall, fatigue parameters through FPBBT have proven the best equipped for predicting asphalt fatigue performance because they can simulate the true fatigue phenomenon of the field in the laboratory, i.e., cyclic loading with constant stress/strain modes to simulate real traffic conditions than the conventional SCB and IDT tests. However, some test conditions' sensitivity (e.g., method of testing and levels of applied strain) need to be investigated further to achieve better correlations with binders-particularly for plastomer-modified binders.

The strain levels of the rheological experiments were found not to significantly impact the correlation with the asphalt crack initiation testing's parameters; both $2.5 \%$ strain and $5 \%$ strain were observed to provide more significant correlation coefficients. However, the correlation coefficients were impacted with high strain levels of LAS when correlating with fatigue cracking properties. The most remarkable correlation of the "All Sources binders" was found with the SCB test. For instance, the $\mathrm{N}_{\mathrm{f}}$ at $5 \%$ of LAS correlated better with the secant modulus than IDT and FPBBT fatigue parameters at $25^{\circ} \mathrm{C}$. Interestingly, the fracture energy of SCB identified the elastomer modified (SBS) blends as the worst-performing material within the tested polymers. In reality, the SCB test, because of the high constant strain mode of testing, could not capture the bitumen recovery component that occurs during the true fatigue phenomenon in the field, making the SCB test not compatible with the fatigue properties of the field.

PV value and loading cycles of the plateau stage of the FPBB test exhibited a moderate to strong correlation with the binder's fatigue life for both "All Sources" and "PMB family" $\left(R^{2}\right.$ greater than 0.60$)$. The strongest correlation $\left(R^{2}=0.82\right)$ for $N_{f}$ at $50 \%$ of asphalt residual stiffness at $400 \mu$ strain vs. $\mathrm{N}_{\mathrm{f}}$ at $2.5 \%$ of binders was found when grouping all tests conducted on "All Sources" (both elastomer and plastomers), probably due to the heterogeneity of the materials tested, which both LAS and FPBBT captured. On the other hand, the CDE of "All Sources" and "PMB family" was weakly correlated (i.e., $R^{2}$ was almost zero) with the binder's fatigue life $\left(R^{2}=0.21-0.69\right)$. A lower correlation of "All Sources" at $400 \mu$ strain was because of the high constant strain mode of testing (high stresses were involved), which expedited the rate of deterioration and produced permanent changes in the asphalt mixtures (unmodified and excessive stiff mixtures); this reduced the recovery properties resulting in premature failure (fewer cycles). On the other hand, the fracture energy of the FPBB test at $300 \mu$ strain was not found as a representative for the "PMB family", as the fracture energy was the product of the stresses and number of cycles, which was underestimated for soft materials. Similarly, the bitumen-asphalt 
test's statistical correlation seemed weak between LAS fatigue life and No. of cycles at $300 \mu$ strain and PV value at $300 \mu$ strain of asphalt mixtures (All Sources and PMB Family). Although the use of No. of cycles, PV value, and CDE in FPBBT ranked the SBSmodified binders as the top-performing material, the SCB and IDT tests assigned SBSmodified asphalt a very low ranking, hence favouring stiffer materials when it comes to testing the asphalt material under very high constant strain. However, the ranking based on FPBBT is closer to those based on LAS fatigue life than IDT and SCB parameters.

The available data indicate that the fatigue life of binders correlates with the fatigue life for mixes made from different polymers and unmodified binders but have similar air voids, sources of aggregates, and gradation. It is possible to design a mixture with a fatigue life that endures a set number of repetitions with the aid of a correlation, as shown in the above table. The amount of data obtained in this investigation was insufficient to permit broad conclusions; however, the results indicate that fatigue life favours the elastomers and underestimates the plastomers' potential for constant strain fatigue tests. However, it is felt that reliable correlations that will indicate fatigue susceptibility can be developed for asphaltic mixtures.

It should be recognised that future studies should pay attention to the following issues to enhance the correlation between binders and asphalt mixture fatigue testing: (1) the difference between a constant strain and constant stress mode tests for FPBB; (2) the use of the lesser rate of deformations for SCB and IDT as a further expression of asphalt cracking resistance; (3) the use of a variety of bitumen content, air voids, and aggregate gradations; and (4) testing at various ageing conditions for bitumen and asphalt mixtures to consider the short- and long-term ageing.

Author Contributions: Conceptualization, M.A.I. and F.G.; methodology, M.A.I. and F.G.; formal analysis, M.A.I.; investigation, M.A.I.; data curation, M.A.I.; writing—original draft preparation, M.A.I.; writing — review and editing, M.A.I. \& F.G.; project administration, F.G.; funding acquisition, F.G. All authors have read and agreed to the published version of the manuscript.

Funding: The study in this paper has been partially funded by the Higher Commission of Education, Pakistan.

Institutional Review Board Statement: Not applicable.

Informed Consent Statement: Not applicable.

Data Availability Statement: The data that support the findings of this study are available from the corresponding author upon reasonable request.

Conflicts of Interest: The authors declare that they have no conflicts of interest.

\section{List of Acronyms}

$\begin{array}{ll}\text { LTPP } & \text { Long-term pavement performance } \\ \text { MFS } & \text { Material fatigue sensitivity } \\ \text { CTOD } & \text { Critical tip opening displacement } \\ \text { DE } & \text { Dissipated energy } \\ \text { FE } & \text { Fracture energy } \\ \text { ALF } & \text { Accelerated loading facility } \\ \text { CDE } & \text { Cumulative dissipated energy } \\ \text { MSCR } & \text { Multiple stress creep recovery } \\ \mathrm{N}_{100} & \text { Number of cycles at a strain level of } 100 \times 10^{-6} \text { in FPBB test } \\ \mathrm{N}_{\mathrm{f}} & \text { Number of cycles to failure (LAS test) } \\ \text { NoC } & \text { Number of cycles to failure (FPBB test) } \\ \text { PG } & \text { Performance grade } \\ \text { PV } & \text { Plateau value } \\ \text { RAS } & \text { Reclaimed asphalt shingles } \\ \text { RBR } & \text { Reclaimed binder ratio } \\ \text { RDEC } & \text { Ratio of dissipated energy change }\end{array}$




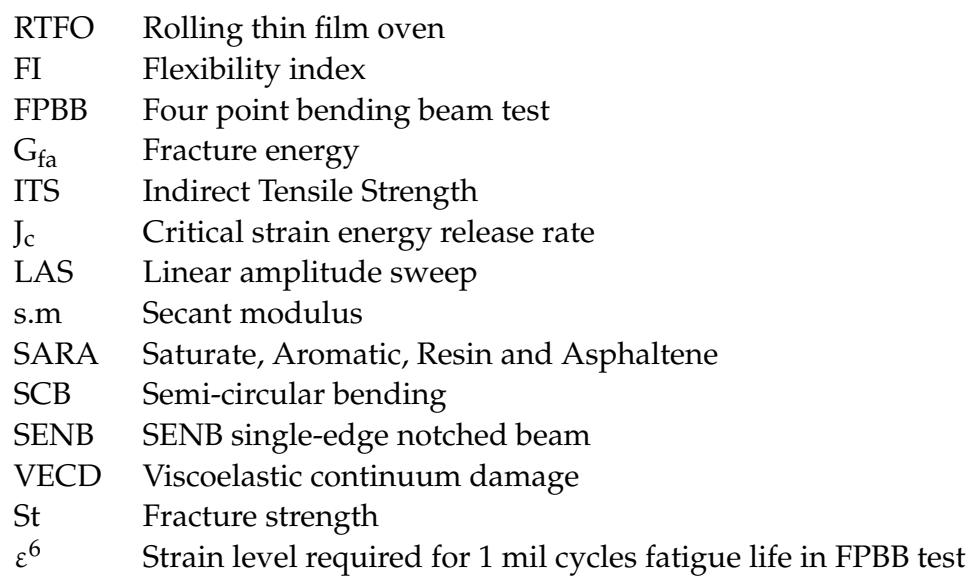

\section{References}

1. NCHRP. Guide for Mechanistic_Empirical Design of New and Rehabilitated Pavement Structures; NCHRP: Washington, DC, USA, 2004.

2. Hafeez, I.; Kamal, M.; Ishaq, M.; Ahmad, N.; Khanzada, S. A laboratory-based research study to investigate the aggregate packing characteristics and its influence on asphaltic mixture's performance. Arab. J. Sci. Eng. 2015, 40, 3119-3134. [CrossRef]

3. Giustozzi, F.J.C.; Materials, B. Polymer-modified pervious concrete for durable and sustainable transportation infrastructures. Constr. Build. Mater. 2016, 111, 502-512. [CrossRef]

4. Ishaq, M.A.; Venturini, L.; Giustozzi, F. Correlation between rheological rutting tests on bitumen and asphalt mix flow number. Int. J. Pavement Res. Technol. 2021. [CrossRef]

5. Ishaq, M.A.; Giustozzi, F. Rejuvenator effectiveness in reducing moisture and freeze/thaw damage on long-term performance of 20\% rap asphalt mixes: An australian case study. Case Stud. in Constr. Mater. 2020, 13, e00454. [CrossRef]

6. Bessa, I.S.; Vasconcelos, K.L.; Castelo Branco, V.T.; Bernucci, L.L. Fatigue resistance of asphalt binders and the correlation with asphalt mixture behaviour. Road Mater. Pavement Des. 2019, 20, S695-S709. [CrossRef]

7. Rahbar-Rastegar, R. Cracking in Asphalt Pavements: Impact of Component Properties and Aging on Fatigue and Thermal Cracking. Ph.D. Thesis, University of New Hampshire, Durham, NH, USA, 2017.

8. Nicholls, C.; Valentin, J.; Soukupova, L.; Mollenhauer, K.; Vansteenkiste, S.; De Visscher, J.; Tušar, M.; Bueche, N.; Bressi, S.; Karcher, C. Identified Correlations between Bitumen and Asphalt Properties (Interim Report); Conference of European Directors of Roads: Brussel, Belgium, 2015.

9. Ragnoli, A.; De Blasiis, M.R.; Di Benedetto, A.J.I. Pavement distress detection methods: A review. Infrastructures 2018, 3, 58. [CrossRef]

10. Cao, W.; Mohammad, L.N.; Barghabany, P. Use of viscoelastic continuum damage theory to correlate fatigue resistance of asphalt binders and mixtures. Int. J. Geomech. 2018, 18, 04018151. [CrossRef]

11. Nizamuddin, S.; Boom, Y.J.; Giustozzi, F.J.P. Sustainable polymers from recycled waste plastics and their virgin counterparts as bitumen modifiers: A comprehensive review. Polymers 2021, 13, 3242. [CrossRef]

12. Lyngdal, E.T. Critical Analysis of pH and PG+ Asphalt Binder Test Methods. Master's Thesis, University of Wisconsin-Madison, Madison, WI, USA, 2015.

13. Roque, R.; Yan, Y.; Lopp, G. Evaluation of the Cracking Performance of Asphalt Binders at Intermediate Temperatures; University of Florida: Gainesville, FL, USA, 2020.

14. Tester, A.M.P. Testing for Fatigue Cracking in the Asphalt Mixture Performance Tester; FHWA: Washington, DC, USA, 2016.

15. Tabatabaee, N.; Tabatabaee, H.A. Multiple stress creep and recovery and time sweep fatigue tests: Crumb rubber modified binder and mixture performance. Transp. Res. Rec. 2010, 2180, 67-74. [CrossRef]

16. Bonicelli, A.; Calvi, P.; Martinez-Arguelles, G.; Fuentes, L.; Giustozzi, F. Experimental study on the use of rejuvenators and plastomeric polymers for improving durability of high RAP content asphalt mixtures. Constr. Build. Mater. 2017, 155, 37-44. [CrossRef]

17. Buche, N.; Valentin, J.; Benešová, L. Correlations between Bitumen and Asphalt Properties; CEDR: Brussels, Belgium, 2016.

18. Timm, D.H.; Robbins, M.M.; Willis, J.R.; Tran, N.; Taylor, A.J. Field and Laboratory Study of High-Polymer Mixtures at the NCAT Test Track; Auburn University: Auburn, AL, USA, 2013.

19. Behnood, A.; Gharehveran, M.M. Morphology, rheology, and physical properties of polymer-modified asphalt binders. Eur. Polym. J. 2019, 112, 766-791. [CrossRef]

20. Chen, J.-S.; Wang, T.J.; Lee, C.-T. Evaluation of a highly-modified asphalt binder for field performance. Constr. Build. Mater. 2018, 171, 539-545. [CrossRef]

21. Habbouche, J.; Hajj, E.Y.; Sebaaly, P.E.; Piratheepan, M. A critical review of high polymer-modified asphalt binders and mixtures. Int. J. Pavement Eng. 2020, 21, 686-702. [CrossRef] 
22. Joohari, I.B.; Giustozzi, F. Hybrid polymerisation: An exploratory study of the chemo-mechanical and rheological properties of hybrid-modified bitumen. Polymers 2020, 12, 945. [CrossRef]

23. D'Angelo, J.; Kluttz, R.; Dongre, R.N.; Stephens, K.; Zanzotto, L. Revision of the superpave high temperature binder specification: The multiple stress creep recovery test (with discussion). J. Assoc. Asph. Paving Technol. 2007, 76, 61-80.

24. Zhang, J.; Walubita, L.F.; Faruk, A.N.; Karki, P.; Simate, G.S. Use of the MSCR test to characterize the asphalt binder properties relative to HMA rutting performance-A laboratory study. Constr. Build. Mater. 2015, 94, 218-227. [CrossRef]

25. Anderson, D.A.; Christensen, D.W.; Bahia, H.U.; Dongre, R.; Sharma, M.; Antle, C.E.; Button, J. Binder Characterization and Evaluation: Physical Characterization; Strategic Highway Research Program: Washington, DC, USA, 1994.

26. Deacon, J.; Harvey, J.; Tayebali, A.; Monismith, C. Influence of binder loss modulus on the fatigue performance of asphalt concrete pavements. J. Assoc. Asph. Paving Technol. 1997, 66, 633-668.

27. Bahia, H.U.; Hanson, D.; Zeng, M.; Zhai, H.; Khatri, M.; Anderson, R. Characterization of Modified Asphalt Binders in Superpave Mix Design; NCHRP: Washington, DC, USA, 2001.

28. Andriescu, A.; Hesp, S.A.; Youtcheff, J.S. Essential and plastic works of ductile fracture in asphalt binders. Transp. Res. Rec. 2004, 1975, 1-7. [CrossRef]

29. Tsai, B.-W.; Monismith, C.L. Influence of asphalt binder properties on the fatigue performance of asphalt concrete pavements. J. Assoc. Asph. Paving Technol. 2005, 74, 733-789.

30. Bahia, H.U.; Zhai, H.; Zeng, M.; Hu, Y.; Turner, P. Development of binder specification parameters based on characterization of damage behavior (with discussion). J. Assoc. Asph. Paving Technol. 2001, 70, 442-470.

31. Bahia, H.; Anderson, D. The new proposed rheological properties of asphalt binders: Why are they required and how do they compare to conventional properties. In Physical Properties of Asphalt Cement Binders; ASTM International: West Conshohocken, PA, USA, 1995.

32. Mullapudi, R.S.; Chowdhury, P.S.; Reddy, K.S. Fatigue and healing characteristics of RAP binder blends. J. Mater. Civ. Eng. 2020, 32, 04020214. [CrossRef]

33. Johnson, C.M. Estimating Asphalt Binder Fatigue Resistance Using an Accelerated Test Method. Ph.D. Thesis, University of Wisconsin-Madison, Madison, WI, USA, 2010.

34. Chehab, G.R.; Seo, Y.; Kim, Y.R. Viscoelastoplastic damage characterization of asphalt-aggregate mixtures using digital image correlation. Int. J. Geomech. 2007, 7, 111-118. [CrossRef]

35. Underwood, B.S.; Baek, C.; Kim, Y.R. Simplified viscoelastic continuum damage model as platform for asphalt concrete fatigue analysis. Transp. Res. Rec. 2012, 2296, 36-45. [CrossRef]

36. Park, H.J.; Eslaminia, M.; Kim, Y.R. Mechanistic evaluation of cracking in in-service asphalt pavements. Mater. Struct. 2014, 47, 1339-1358. [CrossRef]

37. Cao, W.; Norouzi, A.; Kim, Y.R. Application of viscoelastic continuum damage approach to predict fatigue performance of Binzhou perpetual pavements. J. Traffic Transp. Eng. 2016, 3, 104-115. [CrossRef]

38. Hintz, C.; Velasquez, R.; Johnson, C.; Bahia, H. Modification and validation of linear amplitude sweep test for binder fatigue specification. Transp. Res. Rec. 2011, 2207, 99-106. [CrossRef]

39. Zhou, F.; Newcomb, D.; Gurganus, C.; Banihashemrad, S.; Park, E.S.; Sakhaeifar, M.; Lytton, R. Field Validation of Laboratory Tests to Assess Cracking Resistance of Asphalt Mixtures: An Experimental Design; NCHRP: Washington, DC, USA, 2016.

40. Pérez-Jiménez, F.; Valdés, G.; Miró, R.; Martínez, A.; Botella, R. Fénix test: Development of a new test procedure for evaluating cracking resistance in bituminous mixtures. Transp. Res. Rec. 2010, 2181, 36-43. [CrossRef]

41. Kim, H.; Wagoner, M.P.; Buttlar, W.G.J.M. Micromechanical fracture modeling of asphalt concrete using a single-edge notched beam test. Mater. Struct. 2009, 42, 677-689. [CrossRef]

42. Wu, Z.; Mohammad, L.N.; Wang, L.; Mull, M.A. Fracture resistance characterization of superpave mixtures using the semi-circular bending test. J. ASTM Int. 2005, 2, 1-15. [CrossRef]

43. Ozer, H.; Al-Qadi, I.L.; Lambros, J.; El-Khatib, A.; Singhvi, P.; Doll, B. Development of the fracture-based flexibility index for asphalt concrete cracking potential using modified semi-circle bending test parameters. Constr. Build. Mater. 2016, 115, 390-401. [CrossRef]

44. Seitllari, A.; Lanotte, M.; Kutay, M. Comparison of uniaxial tension-compression fatigue test results with SCB test performance indicators developed for performance-based mix design procedure. In Bituminous Mixtures and Pavements VII, Proceedings of the 7th International Conference 'Bituminous Mixtures and Pavements' (7ICONFBMP), Thessaloniki, Greece, 12-14 June 2019; CRC Press: Boca Raton, FL, USA, 2019.

45. Koh, C.; Lopp, G.; Roque, R. Development of a dog-bone direct tension test (DBDT) for asphalt concrete. In Advanced Testing and Characterization of Bituminous Materials; CRC Press: Boca Raton, FL, USA, 2009; pp. 601-612.

46. Zhou, F.; Hu, S.; Chen, D.-H.; Scullion, T. Overlay tester: Simple performance test for fatigue cracking. Transp. Res. Rec. 2007, 2001, 1-8. [CrossRef]

47. Walubita, L.F.; Faruk, A.N.; Alvarez, A.E.; Scullion, T. The Overlay Tester (OT): Using the Fracture Energy Index concept to analyze the OT monotonic loading test data. Constr. Build. Mater. 2013, 40, 802-811. [CrossRef]

48. Roque, R.; Buttlar, W.G. Development of a measurement and analysis system to accurately determine asphalt concrete properties using the indirect tensile mode. In Asphalt Paving Technology: Association of Asphalt Paving Technologists—Proceedings of the Technical Sessions; Association of Asphalt Paving Technologists: White Bear Lake, MN, USA, 1992. 
49. Wagnoner, M.; Buttlar, W.G.; Paulino, G.H. Disk-shaped compact tension test for asphalt concrete fracture. Exp. Mech. 2005, 45, 270-277. [CrossRef]

50. Kim, Y.R.; Wen, H. Fracture energy from indirect tension testing. J. Assoc. Asph. Paving Technol. 2002, 71, 779-793.

51. Zhou, F.; Im, S.; Sun, L.; Scullion, T. Development of an IDEAL cracking test for asphalt mix design and QC/QA. Road Mater. Pavement Des. 2017, 18, 405-427. [CrossRef]

52. Braham, A. State of the Art and Practice in Fatigue Cracking Evaluation of Asphalt Concrete Pavements; Association of Asphalt Paving Technologists: White Bear Lake, MN, USA, 2016.

53. Mandal, T.; Ling, C.; Chaturabong, P.; Bahia, H.U. Evaluation of analysis methods of the semi-circular bend (SCB) test results for measuring cracking resistance of asphalt mixtures. Int. J. Pavement Res. Technol. 2019, 12, 456-463. [CrossRef]

54. Bayomy, F.; Mull-Aglan, M.A.; Abdo, A.A.; Santi, M.J. Evaluation of hot mix asphalt (HMA) fracture resistance using the critical strain energy release rate, Jc. In Proceedings of the Transportation Research Board 85th Annual Meeting, Washington, DC, USA, 22-26 January 2006.

55. McLeod, N.W. A 4-year survey of low temperature transverse pavement cracking on the three Ontario test roads. In Asphalt Paving Technology: Association of Asphalt Paving Technologists_Proceedings of the Technical Sessions; Association of Asphalt Paving Technologists: White Bear Lake, MN, USA, 1972.

56. Cao, W.; Mohammad, L.N.; Elseifi, M.; Cooper III, S.B.; Saadeh, S. Fatigue performance prediction of asphalt pavement based on semicircular bending test at intermediate temperature. J. Mater. Civ. Eng. 2018, 30, 04018219. [CrossRef]

57. Seitllari, A.; Boz, I.; Habbouche, J.; Diefenderfer, S.D. Assessment of cracking performance indices of asphalt mixtures at intermediate temperatures. Int. J. Pavement Eng. 2020, 23, 70-79. [CrossRef]

58. Bennert, T.; Haas, E.; Wass, E. Indirect tensile test (IDT) to determine asphalt mixture performance indicators during quality control testing in New Jersey. Transp. Res. Rec. 2018, 2672, 394-403. [CrossRef]

59. Arabani, M.; Ferdowsi, B. Evaluating the semi-circular bending test for HMA mixtures. Int. J. Eng. 2017, 8, 1164-1175.

60. Flintsch, G.W.; Al-Qadi, I.L.; Loulizi, A.; Mokarem, D.W. Laboratory Tests for Hot-Mix Asphalt Characterization in Virginia. 2005. Available online: https:/ /vtechworks.lib.vt.edu/handle/10919/46688?show=full (accessed on 22 October 2021).

61. Fakhri, M. Characterisation of Asphalt Pavement Materials. 1999. Available online: http://unsworks.unsw.edu.au/fapi/ datastream/unsworks:37785/SOURCE01?view=true (accessed on 22 October 2021).

62. Di Benedetto, H.; De La Roche, C.; Baaj, H.; Pronk, A.; Lundström, R. Fatigue of bituminous mixtures. Mater. Struct. 2004, 37, 202-216. [CrossRef]

63. Di Benedetto, H.; de La Roche, C.; Baaj, H.; Pronk, A.; Lundstrom, R. Fatigue of bituminous mixtures: Different approaches and RILEM group contribution. In Proceedings of the Sixth International RILEM Symposium on Performance Testing and Evaluation of Bituminous Materials, Zurich, Switzerland, 14-16 April 2003.

64. Kutay, M.E.; Gibson, N.H.; Youtcheff, J. Conventional and viscoelastic continuum damage (VECD)-based fatigue analysis of polymer modified asphalt pavements (with discussion). J. Assoc. Asph. Paving Technol. 2008, 77, 395-434.

65. Austroads. Characterisation of Flexural Stiffness and Fatigue Performance of Bituminous Mixes; Austroads: Sydney, Australia, 2016.

66. ASTM. Standard Test Method for Determining Fatigue Failure of Asphalt-Aggregate Mixtures with the Four-Point Beam Fatigue Device; ASTM International: West Conshohocken, PA, USA, 2018.

67. BSI. Bituminous Mixtures. Test Methods. Resistance to Fatigue; BSI: London, UK, 2018.

68. Harvey, J.; Monismith, C.L. Effects of laboratory asphalt concrete specimen preparation variables on fatigue and permanent deformation test results using strategic highway research program a-003a proposed testing equipment. In Transportation Research Record; Institute of Transportation Studies, University of California at Berkeley: Berkeley, CA, USA, 1993.

69. Coni, M.; Portas, S.; Isola, R.; Oliveira, J. FE evaluation of 4-point bending test for fatigue cracking assessment. In Pavement Cracking: Mechanisms, Modeling, Detection, Testing Case Histories; CRC Press: Boca Raton, FL, USA, 2008; pp. $271-281$.

70. Huang, Y.H. Pavement Design and Analysis; Pearson: London, UK, 2004.

71. Jones, D.; Wu, R.; Barros, C. Interim results from the California warm-mix asphalt study. In Proceedings of the 24th ARRB Conference, Melbourne, Australia, 13-15 October 2010.

72. Mohammad, L. Design and Analysis Procedures for Asphalt Mixtures Containing High RAP Contents and/or RAS; Louisiana Transportation Research Center: Baton Rouge, LA, USA, 2015.

73. Clopotel, C.S.; Velasquez, R.; Bahia, H.U.; Pérez-Jiménez, F.; Miró, R.; Botella, R. Relationship between binder and mixture damage resistance at intermediate and low temperatures. Transp. Res. Rec. 2012, 2293, 39-47. [CrossRef]

74. Zhou, F.; Mogawer, W.; Li, H.; Andriescu, A.; Copeland, A. Evaluation of fatigue tests for characterizing asphalt binders. J. Mater. Civ. Eng. 2013, 25, 610-617. [CrossRef]

75. Mannan, U.A.; Islam, M.R.; Tarefder, R.A. Effects of recycled asphalt pavements on the fatigue life of asphalt under different strain levels and loading frequencies. Int. J. Fatigue 2015, 78, 72-80. [CrossRef]

76. Johnson, C.; Bahia, H.; Coenen, A. Comparison of bitumen fatigue testing procedures measured in shear and correlations with four-point bending mixture fatigue. In Proceedings of the 2nd Workshop on Four Point Bending, Guimaraes, Portugal, 24-25 September 2009.

77. Daryaee, D.; Ameri, M. Evaluation of the correlation between performance parameters of asphalt binder and mixture in the RAP-containing asphalt mixtures. Amirkabir J. Civ. Eng. 2021, 53, 6. 
78. Sabouri, M.; Mirzaiyan, D.; Moniri, A.J.C. Effectiveness of Linear Amplitude Sweep (LAS) asphalt binder test in predicting asphalt mixtures fatigue performance. Constr. Build. Mater. 2018, 171, 281-290. [CrossRef]

79. Ameri, M.; Nowbakht, S.; Molayem, M.; Mirabimoghaddam, M.H. A study on fatigue modeling of hot mix asphalt mixtures based on the viscoelastic continuum damage properties of asphalt binder. Constr. Build. Mater. 2016, 106, 243-252. [CrossRef]

80. Wang, C.; Castorena, C.; Zhang, J.; Richard Kim, Y. Unified failure criterion for asphalt binder under cyclic fatigue loading. Road Mater. Pavement Des. 2015, 16, 125-148. [CrossRef]

81. Safaei, F.; Lee, J.-s.; Nascimento, L.A.H.d.; Hintz, C.; Kim, Y.R. Implications of warm-mix asphalt on long-term oxidative ageing and fatigue performance of asphalt binders and mixtures. Road Mater. Pavement Des. 2014, 15, 45-61. [CrossRef]

82. Johnson, C.; Bahia, H.U. Evaluation of an accelerated procedure for fatigue characterization of asphalt binders. Road Mater. Pavement Des. 2010, X, $201 Z$.

83. Saboo, N.; Kumar, P. Performance characterization of polymer modified asphalt binders and mixes. Adv. Civ. Eng. 2016, 2016, 5938270. [CrossRef]

84. Foroutan Mirhosseini, A.; Kavussi, A.; Jalal Kamali, M.H.; Khabiri, M.M.; Hassani, A. Evaluating fatigue behavior of asphalt binders and mixes containing Date Seed Ash. J. Civ. Eng. Manag. 2017, 23, 1164-1175. [CrossRef]

85. Hasaninia, M.; Haddadi, F.J. Studying engineering characteristics of asphalt binder and mixture modified by nanosilica and estimating their correlations. Adv. Mater. Sci. Eng. 2018, 2018, 4560101. [CrossRef]

86. Standards Australia. AS/NZS 2891.3.3:2013-Methods of Sampling and Testing Asphalt Binder Content and Aggregate Grading-Pressure Filter Method; Standards Australia: Sydney, Australia, 2013.

87. American Association of State Highway Transportation Officials. Standard Method of Test for Estimating Fatigue Resistance of Asphalt Binders Using the Linear Amplitude Sweep; American Association of State Highway Transportation Officials: Washington, DC, USA, 2012.

88. Kim, Y.R.; Lee, H.-J.; Little, D.N. Fatigue characterization of asphalt concrete using viscoelasticity and continuum damage theory (with discussion). J. Assoc. Asph. Paving Technol. 1997, 66, 520-569.

89. American Association of State Highway Transportation Officials. 124-16. Determining the Fracture Potential of Asphalt Mixtures Using Semicircular Bend Geometry (SCB) at Intermediate Temperature; AASHTO: Washington, DC, USA, 2016.

90. Al-Qadi, I.L.; Ozer, H.; Lambros, J.; El Khatib, A.; Singhvi, P.; Khan, T.; Rivera-Perez, J.; Doll, B. Testing Protocols to Ensure Performance of High Asphalt Binder Replacement Mixes Using RAP and RAS; Illinois Center for Transportation/Illinois Department of Transportation: Rantoul, IL, USA, 2015.

91. Ozer, H.; Al-Qadi, I.L.; Singhvi, P.; Khan, T.; Rivera-Perez, J.; El-Khatib, A. Fracture characterization of asphalt mixtures with high recycled content using Illinois semicircular bending test method and flexibility index. Transp. Res. Rec. 2016, 2575, 130-137. [CrossRef]

92. Hillerborg, A. The theoretical basis of a method to determine the fracture energy GF of concrete. Mater. Struct. 1985, 18, 291-296. [CrossRef]

93. Bažant, Z.P. Analysis of work-of-fracture method for measuring fracture energy of concrete. J. Eng. Mech. 1996, 122, 138-144. [CrossRef]

94. Carpenter, S.H.; Ghuzlan, K.A.; Shen, S. Fatigue endurance limit for highway and airport pavements. Transp. Res. Rec. 2003, 1832, 131-138. [CrossRef]

95. Francken, L. Permanent deformation law of bituminous road mixes in repeated triaxial compression. In Proceedings of the 4th International Conference on Structural Design of Asphalt Pavements, Ann Arbor, MI, USA, 22-26 August 1977.

96. Carpenter, S.H.; Shen, S. Dissipated energy approach to study hot-mix asphalt healing in fatigue. Transp. Res. Rec. 2006, 1970, 178-185. [CrossRef]

97. Shen, S.; Carpenter, S.H. Application of the dissipated energy concept in fatigue endurance limit testing. Transp. Res. Rec. 2005, 1929, 165-173. [CrossRef]

98. Heinze, G.; Dunkler, D. Five myths about variable selection. Transpl. Int. 2017, 30, 6-10. [CrossRef] [PubMed]

99. Ziari, H.; Amini, A.; Goli, A.J.C.; Materials, B. The effect of different aging conditions and strain levels on relationship between fatigue life of asphalt binders and mixtures. Constr. Build. Mater. 2020, 244, 118345. [CrossRef]

100. Wekumbura, C.; Stastna, J.; Zanzotto, L. Destruction and recovery of internal structure in polymer-modified asphalts. J. Mater. Civ. Eng. 2007, 19, 227-232. [CrossRef]

101. Bui, H.H.; Saleh, M. Effects of specimen size and loading conditions on the fracture behaviour of asphalt concretes in the SCB test. Eng. Fract. Mech. 2021, 242, 107452. 